\title{
Multiobjective Optimization Based on "Distance-to-Target" Approach of Membrane Units for Separation of $\mathrm{CO}_{2} / \mathrm{CH}_{4}$
}

\author{
Ricardo Abejón $^{1,2, *\left(\mathbb{D}, \text { Clara Casado-Coterillo }^{1} \mathbb{D} \text { and Aurora Garea }\right.}{ }^{1}$ D \\ 1 Departamento de Ingenierías Química y Biomolecular, Universidad de Cantabria, Av. Los Castros s/n, \\ 39005 Santander, Spain; casadoc@unican.es (C.C.-C.); gareaa@unican.es (A.G.) \\ 2 Departamento de Ingeniería Química, Universidad de Santiago de Chile, Av. Libertador Bernardo O'Higgins \\ 3363, Estación Central, Santiago 9170019, Chile \\ * Correspondence: ricardo.abejon@usach.cl
}

Citation: Abejón, R.;

Casado-Coterillo, C.; Garea, A.

Multiobjective Optimization Based on

"Distance-to-Target" Approach of Membrane Units for Separation of $\mathrm{CO}_{2} / \mathrm{CH}_{4}$. Processes 2021, 9, 1871.

https://doi.org/10.3390/pr9111871

Academic Editor:

Fabricio Napoles-Rivera

Received: 2 September 2021

Accepted: 19 October 2021

Published: 21 October 2021

Publisher's Note: MDPI stays neutral with regard to jurisdictional claims in published maps and institutional affiliations.

Copyright: (c) 2021 by the authors. Licensee MDPI, Basel, Switzerland This article is an open access article distributed under the terms and conditions of the Creative Commons Attribution (CC BY) license (https:// creativecommons.org/licenses/by/ $4.0 /)$

\begin{abstract}
The effective separation of $\mathrm{CO}_{2}$ and $\mathrm{CH}_{4}$ mixtures is essential for many applications, such as biogas upgrading, natural gas sweetening or enhanced oil recovery. Membrane separations can contribute greatly in these tasks, and innovative membrane materials are being developed for this gas separation. The aim of this work is the evaluation of the potential of two types of highly $\mathrm{CO}_{2}$-permeable membranes (modified commercial polydimethylsiloxane and non-commercial ionic liquid-chitosan composite membranes) whose selective layers possess different hydrophobic and hydrophilic characteristics for the separation of $\mathrm{CO}_{2} / \mathrm{CH}_{4}$ mixtures. The study of the technical performance of the selected membranes can provide a better understanding of their potentiality. The optimization of the performance of hollow fiber modules for both types of membranes was carried out by a "distance-to-target" approach that considered multiple objectives related to the purities and recovery of both gases. The results demonstrated that the ionic liquid-chitosan composite membranes improved the performance of other innovative membranes, with purity and recovery percentage values of 86 and $95 \%$, respectively, for $\mathrm{CO}_{2}$ in the permeate stream, and 97 and $92 \%$ for $\mathrm{CH}_{4}$ in the retentate stream. The developed multiobjective optimization allowed for the determination of the optimal process design and performance parameters, such as the membrane area, pressure ratio and stage cut required to achieve maximum values for component separation in terms of purity and recovery. Since the purities and recoveries obtained were not enough to fulfill the requirements imposed on $\mathrm{CO}_{2}$ and $\mathrm{CH}_{4}$ streams to be directly valorized, the design of more complex multi-stage separation systems was also proposed by the application of this optimization methodology, which is considered as a useful tool to advance the implementation of the membrane separation processes.
\end{abstract}

Keywords: gas separation; membranes; $\mathrm{CO}_{2} ; \mathrm{CH}_{4}$; hollow fibers; "distance to target" multiobjective optimization

\section{Introduction}

Membrane separation processes are considered to be of great potential in addressing the drawbacks of conventionally based amine processes for $\mathrm{CO}_{2}$ capture and for natural gas sweetening or biogas upgrading [1,2]. For the separation of $\mathrm{CO}_{2}$ from $\mathrm{CH}_{4}$, the first biogas upgrading plants were installed with technologies used in the natural gas industrial processing. For biogas upgradation, several technologies are currently available, ranging from absorption, adsorption and membrane-based gas permeation; in addition, advancements are being made in the direction of cryogenic separation, in situ methane enrichment and hybrid membrane-cryogenic technologies. The market situation for biogas upgrading has changed rapidly in recent years, making membrane separation achieve a significant market share with traditional biogas upgrading technologies [3,4]. Membrane gas separation is a mature and expanding technology, as covered in the perspective analysis performed by Galizia et al. [5], who pointed out that the availability of better membrane 
materials, meaning a higher permeation without compromising selectivity and stability, would promote faster growth.

The separation mechanism of a membrane gas permeation is usually a compromise between selectivity and permeability, which are the key parameters of the membrane performance. Remarking some studies that compiled and reviewed membrane materials for $\mathrm{CO}_{2} / \mathrm{CH}_{4}$ separation [6-10], the characteristics of some representative materials were given in terms of $\mathrm{CO}_{2}$ permeability and ideal selectivity $\left(\mathrm{CO}_{2} / \mathrm{CH}_{4}\right)$. Among the most representative materials studied for $\mathrm{CO}_{2} / \mathrm{CH}_{4}$ separation, it was pointed out that cellulose acetate was the most used polymer for large scale $\mathrm{CO}_{2}$ separation, despite a significant selectivity reduction when processing a highly pressurized natural gas mixture in comparison to single gas permeability data. This is due to a possible effect of plasticization, it being the scope for investigating other polymeric materials that are more stable at process conditions, such as polydimethylsiloxane (PDMS) [11]. The development of new membrane materials, including polymers and hybrid materials, will rely on a multidisciplinary approach that embraces the broad fields of chemical and materials engineering, polymer science and materials chemistry, as well as accurate process understanding in order to close the gap with their implementation in large scale applications [5,12].

A major challenge for developing effective gas separation membranes is overcoming the well-known permeability-selectivity trade-off for light gases in polymeric materials, which leads to an upper bound that serves as reference for evaluating the advances in highly permselective membrane materials, and, in turn, influencing the material design [13-16]. The efforts for enhanced $\mathrm{CO}_{2} / \mathrm{CH}_{4}$ separation have been focused on the development of large-scale projects by improving stability and efficiency, which are linked to the innovation of materials, thermally rearranged (TR) polymers, polymers of intrinsic microporosity (PIM), which are two types of polymers that consistently perform at or beyond the polymer upper bound for certain gas pairs $\left(\mathrm{O}_{2} / \mathrm{N}_{2}\right.$ and $\left.\mathrm{CO}_{2} / \mathrm{CH}_{4}\right)$, biopolymer-based membranes and mixed matrix membranes (MMM) formulations and blending systems, where ionic liquids were included $[14,15,17-24]$. The routes to develop better membranes were covered in these referenced reviews, which introduce some large-scale applications where better membranes based on new advanced materials could be implemented. Five different approaches to better materials have been described: (i) unconventional-conventional polymers, (ii) nano-porous polymers with PIMs and TR polymers as examples, (iii) facilitated transport materials, (iv) mixed matrix membranes that are also revitalized by new sieve materials, such as metal-organic frameworks (MOFs), and (v) inorganic membranes with excellent stability but scale-up difficulties. From a series of large gas separation applications where better membranes would either greatly expand their use or allow for entry into a new market, an estimation of the membrane permeance and selectivity required to achieve commercial viability was included [5]. The target membrane performance for the competitive separation of $\mathrm{CO}_{2} / \mathrm{CH}_{4}$ in $\mathrm{CO}_{2}$ removal from natural gas required a selectivity in the range of 20-30 and a $\mathrm{CO}_{2}$ permeance above $100 \mathrm{GPU}$ in order to capture a portion of the much larger amine absorption market.

Superglassy membranes have also been proposed in hybrid membrane/amine processes for natural gas sweetening, as reported recently [25], with recommendations for further research on producing mixed matrix membranes of superglassy polymers with anti-aging properties, mixing superglassy polymers with porous and non-porous fillers to overcome physical aging and thin film composite membranes.

The hydrophobic or hydrophilic character of the membranes was also considered of relevance, as they were affected differently to the $\mathrm{CO}_{2}$ and $\mathrm{CH}_{4}$ permeances in the presence of impurities (such as water vapor or other non-methane hydrocarbons as minor components). The hydrophilicity can be tuned up by modifying the membrane material composition, covered in more detail in recent publications related to mixed matrix membranes [26-28], resulting in the innovation of materials that may contribute to the integration of the membrane technology in real scale production plants. Multilayer composite membranes also offer the possibility to optimize membrane layer materials independently, 
allowing for the transfer of the selective layer properties to different geometries, which could be more easily implemented at a large scale [29].

The outlook related to the opportunities for advancing membranes given by Park et al. [16] included the tasks of modeling at all length scales as needed in order to develop a coherent molecular understanding of key features, from membrane properties, which provide insight for future materials design, to membrane configuration and module design, as well as the membrane process optimization (operating conditions, product quality targets). Remarking the efforts toward the modeling and optimization tasks in conjunction with the materials innovation aspects, Ohs et al. [30] demonstrated the use of upper-bound properties of membranes coupled with process modeling to identify economically optimal combinations of permeability and selectivity in the reported study for nitrogen removal from natural gas. Such studies for other gas separations of interest would be desirable in order to provide appropriate targets for materials design, show the opportunities for membranes in both existing and emerging applications and implement the methodologies to scale promising membranes from laboratory studies to the thousands of square meters needed for large applications. All of these purposes need the modeling and optimization tasks for the process design to effectively address separation requirements.

Taking into account the remarked keys, the main objective of this work is to realize a complete comparison of the performance of different non-commercial $\mathrm{CO}_{2} / \mathrm{CH}_{4}$ selective membranes (modified commercial hydrophobic PDMS and non-commercial hydrophilic ionic liquid-chitosan (IL-CS) composite membranes previously developed and characterized by this research group) and to identify the optimal design and operation conditions that maximize their technical performance.

The membranes used for this study are flat-sheet composite membranes, the commercial PERVAP 4060 (DeltaMem AG, CH-Allschwil) with a 1-1.5 $\mu$ m thick PDMS top layer and a total thickness of $180 \mu \mathrm{m}$, which was also modified by a $\mathrm{NaOH}$ treatment in order to enhance the attraction of $\mathrm{CO}_{2}$ more preferentially and a self-prepared IL-CS/PES composite membrane fabricated in our laboratory with a similar selective layer thickness as the commercial hydrophobic membrane.

These membranes were selected due to their promising permeance and selectivity from gas permeation studies covering the separations of $\mathrm{CO}_{2} / \mathrm{N}_{2}$ and $\mathrm{CO}_{2} / \mathrm{CH}_{4}$ in previous works of the research group [24,28], focusing, in this study, on (i) the modification of a commercial PDMS membrane by a $\mathrm{NaOH}$ treatment to attract $\mathrm{CO}_{2}$ preferentially, and (ii) the use of a biopolymer-based membrane (with ionic liquid inclusion) in a robust support as the proposed options for tuning up the membrane separation properties. The performance of these membranes from single gas permeation tests and the surface characterization studies by ATR-FTIR were also reported elsewhere, the $\mathrm{NaOH}$ treatment being remarkable, and the enhanced $\mathrm{CO}_{2} / \mathrm{CH}_{4}$ separation ability of the membranes containing ionic liquid due to the strong absorption selectivity towards $\mathrm{CO}_{2}$. The effect of the ionic liquid addition was also reported in the literature [31,32], with the use of room temperature ionic liquids to improve the interphase morphologies of membranes in mixed matrix membranes, and the study of gas transport properties of tailored $\mathrm{CO}_{2}$-philic anionic poly (ionic liquid) composite membranes. The hybridization effect of chitosan (CS) by introducing a determined percentage by weight of a highly $\mathrm{CO}_{2}$-absorbing ionic liquid was further considered in order to improve the selectivity of pure CS membranes.

Since the optimization of the performance of a membrane module for gas separation is not a trivial task (multiple objectives related to the purities and recoveries of the different gases present in the mixture must be considered), a "distance-to-target" approach can provide valuable results. Standard multiobjective optimization methods, such as $\varepsilon$ constraints, result in Pareto fronts when applied to two objectives, or Pareto surfaces when three objectives are considered [33,34]. In these Pareto solutions, none of the conflicting objective functions can be improved in value without degrading some of the other objective values. However, when more than three objectives are simultaneously considered, the corresponding Pareto sets of solutions become more complex and cannot be translated as a 
simple graphical representation. Besides, if additional subjective preference information is not defined, all of the Pareto solutions can be considered equally good, and the selection of the optimal conditions of a preferred unique solution is not direct. In contrast, a "distance to target" approach provides some advantages when compared to the mentioned standard multiobjective optimization methods [35]. For example, this approach provides a single Pareto solution rather than Pareto sets of solutions regardless of the numbers of objectives defined. As this optimization approach provides practical guidelines by measuring and quantifying the magnitude toward previously defined targets, this single Pareto solution is determined by the minimization of its distance to the objective values. Consequently, the "distance to target" approach applied in this work provides a better scenario for the direct comparison of the several alternative membranes for the separation of gas mixtures.

\section{Modeling}

\subsection{Model Development}

Although there are numerous models reported in the literature for gas separation by hollow fiber permeators, most of them are based on a differential approach [36]. Typically, a set of coupled nonlinear differential equations are solved to define the module performance. The resulting set of differential equations, together with the specified feed flow rate, pressure and composition, as well as the permeate outlet pressure, form a boundary value problem. Iterative techniques can be used to solve these problems, but this methodology can be burdensome when complex considerations are taken into account, such as multicomponent mixtures, non-constant permeability coefficients, temperature effects or multi-stage configurations. As a result of these reasons, an alternative strategy has been adopted in this work. The representative hollow fiber is divided into a series of $\mathrm{n}$ perfectly mixed stages in the axial direction, and mass balances are enforced in each section. This procedure is formally equivalent to using first order finite differences to develop a set of coupled difference equations from the differential mass balances for this problem [37]. The bore-side feed countercurrent flow arrangement is the most frequently used configuration for gas separation using asymmetric hollow fiber membranes, and a mathematical model is thus developed here for this configuration (Figure 1). The main assumptions employed in the model development are:

- The deformation of the hollow fibers under pressure is negligible;

- The membrane permeability is independent of the concentration and pressure;

- The pressure changes in the retentate and permeate streams in the lumen and shell sides are negligible;

- The concentration polarization on both sides of the membrane is negligible;

- The gas flows are evenly distributed, and the end effects resulting from flow direction changes are negligible;

- The gas on the lumen and shell sides of the hollow fibers is in a plug flow;

- The membrane module is operated at a steady state.

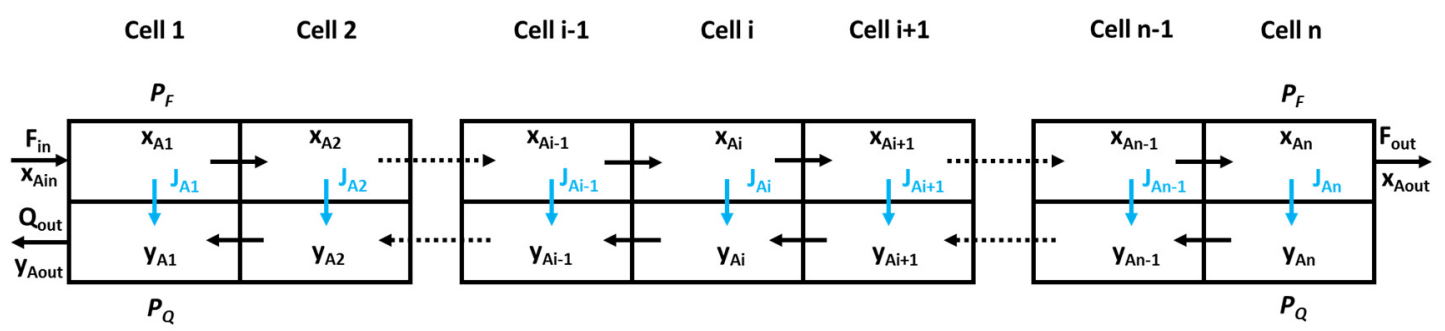

Figure 1. Scheme of the bore-side feed countercurrent flow arrangement considered in this work.

The model is based on the corresponding global and by components material balances to the module and the $\mathrm{n}$ stages, coupled with the definition of the gas permeation through 
the membrane. Only the equations for the most permeable component $\mathrm{A}$ are described here in details, and the equations of the least permeable compound B are equivalent:

Material balances on the module

$$
\begin{gathered}
F_{\text {in }}=F_{\text {out }}+Q_{\text {out }} \\
F_{\text {in }} \cdot x_{\text {Ain }}=F_{\text {out }} \cdot x_{\text {Aout }}+Q_{\text {out }} \cdot y_{\text {Aout }} \\
F_{\text {in }} \cdot x_{\text {Bin }}=F_{\text {out }} \cdot x_{\text {Bout }}+Q_{\text {out }} \cdot y_{\text {Bout }}
\end{gathered}
$$

Material balances on the cell (global, on the tube side and on the shell side)

$$
\begin{gathered}
F_{\text {in }(i)}+Q_{\text {in }(i)}=F_{\text {out }(i)}+Q_{\text {out }(i)} \\
F_{\text {in }(i)}=F_{\text {out }(i)}+J_{(i)} \\
Q_{\text {in }(i)}+J_{(i)}=Q_{\text {out }(i)}
\end{gathered}
$$

Flow across the membrane

$$
\begin{gathered}
J_{(i)}=J_{A(i)}+J_{B(i)} \\
J_{A(i)}=\operatorname{Perm}_{A} \cdot A_{M} \cdot\left(P_{F} \cdot x_{A(i)}-P_{Q} \cdot y_{A(i)}\right) \\
J_{B(i)}=\operatorname{Perm}_{B} \cdot A_{M} \cdot\left(P_{F} \cdot x_{B(i)}-P_{Q} \cdot y_{B(i)}\right)
\end{gathered}
$$

Cell continuity

$$
\begin{aligned}
& F_{\text {in }(i)}=F_{\text {out }(i-1)} \\
& x_{A i n(i)}=x_{A(i-1)} \\
& Q_{\text {in }(i)}=Q_{\text {out }(i+1)} \\
& y_{\text {Ain }(i)}=y_{A(i+1)}
\end{aligned}
$$

Relationship between individual and total flows (definition of molar fractions)

$$
\begin{gathered}
F_{\text {Ain }(i)}=F_{\text {in }(i)} \cdot x_{A(i-1)} \\
F_{\text {Aout }(i)}=F_{\text {out }(i)} \cdot x_{A(i)} \\
Q_{\text {Ain }(i)}=Q_{\text {in }(i)} \cdot y_{A(i+1)} \\
Q_{\text {Aout }(i)}=Q_{\text {out }(i)} \cdot y_{A(i)}
\end{gathered}
$$

Membrane transport properties: the number 2736 in Equation (18) is the conversion factor from the membrane permeability (Perm) expressed in GPU to specific gas permeabilities $\left(\right.$ Perm $_{A}$ and Perm $\left._{B}\right)$ expressed in $\mathrm{m}^{3}{ }_{(\mathrm{STP})} / \mathrm{m}^{2} \cdot \mathrm{h} \cdot \mathrm{atm}\left(1 \mathrm{~m}^{3}{ }_{(\mathrm{STP})} / \mathrm{m}^{2} \cdot \mathrm{h} \cdot \mathrm{atm}=2736\right.$ GPU)

$$
\begin{aligned}
\operatorname{Perm}_{A} & =\frac{\text { Perm }}{2736} \\
\operatorname{Perm}_{B} & =\frac{\text { Perm }}{\alpha}
\end{aligned}
$$

Definition of process design and performance parameters.

$$
\begin{gathered}
\text { Purity }_{A}=100 \cdot \frac{Q_{\text {Aout }}}{Q_{\text {out }}}=100 \cdot \frac{Q_{\text {out }} \cdot y_{\text {Aout }}}{Q_{\text {out }}}=100 \cdot y_{\text {Aout }} \\
\text { Recovery }_{A}=100 \cdot \frac{Q_{\text {Aout }}}{F_{\text {Ain }}}=100 \cdot \frac{Q_{\text {out }} \cdot y_{\text {Aout }}}{F_{\text {in }} \cdot x_{\text {Ain }}}
\end{gathered}
$$




$$
\begin{gathered}
\text { Purity }_{B}=100 \cdot \frac{F_{\text {Bout }}}{F_{\text {out }}}=100 \cdot \frac{F_{\text {out }} \cdot x_{\text {Bout }}}{F_{\text {out }}}=100 \cdot x_{\text {Bout }} \\
\text { Recovery }_{B}=100 \cdot \frac{F_{\text {Bout }}}{F_{\text {Bin }}}=100 \cdot \frac{F_{\text {out }} \cdot x_{\text {Bout }}}{F_{\text {in }} \cdot x_{\text {Bin }}} \\
\text { Stage cut }=\frac{Q_{\text {out }}}{F_{\text {in }}}
\end{gathered}
$$

These defined purities and recoveries must be considered as the main indicators of the performance of the separation process, and specifications can be fixed to these parameters. Therefore, the optimization of the process will focus on the achievement of maximal purities and recoveries as functions of the optimal pressures on both sides of the membrane and the module stage cut (which defined the total membrane area of the module) for each feed composition. However, the optimization of the design and operation of a hollow fiber module for gas separation is not a trivial task. In most cases, both gases are considered products, and, consequently, purity and recovery requirements will be imposed. In these circumstances, contradictory objectives must be counterbalanced, since it is not possible to maximize purity and recovery simultaneously. Therefore, a multiobjective problem must be defined, with at least four different conflicting targets (purities and recoveries of both gases), although a higher number of objectives could appear if the membrane area, energy consumption or economic aspects are considered as additional relevant targets. The discarding of standard multiobjective optimization methods, such as $\varepsilon$-constraints, can be justified in order to overcome this drawback, by proposing a methodology based on a "distance-to-target" approach. For example, this approach can provide a single Pareto solution rather than Pareto sets of solutions based on the distance to the objective values. In addition, this approach is more adequate in identifying the best way to improve suboptimal solutions by finding minimal projections onto the optimal limits [38]. The Euclidean distance between the individual solutions and the optimization targets of a problem can be used as base of this approach [39]. The Euclidean distance $\mathrm{D}$ in an n-dimension space is defined by Equation (25):

$$
D=\sqrt{\sum_{i}^{n}\left(C_{i}-G_{i}\right)^{2}}
$$

where $C_{i}$ are the components of the vector to be optimized and $G_{i}$ are those of the specified target. In this work, the components of the vector target include the purities and recoveries of both gases present in the $\mathrm{CO}_{2} / \mathrm{CH}_{4}$ mixture. In the current study, a normalized equally weighted distance $D_{N}$ was employed as the main indicator to identify the optimal performance of the gas separation process, applying Equation (26):

$$
D_{N}=\frac{D}{100 \cdot \sqrt{n}}=\frac{\sqrt{\sum\left(C_{i}-G_{i}\right)^{2}}}{100 \cdot \sqrt{n}}
$$

where $\mathrm{n}$ represents the number of dimensions of the space (number of objectives). Since the four objectives considered in this work were percentages, the presence of 100 in the denominator implied that the definition of $D_{N}$ warranted the distance values to be normalized in the range between 0 (closest to the target) and 1 (furthest to the target), so a direct and easily comparable outlook of the results was obtained (another clear advantage over conventional multiobjective optimization methods). In this case, since the four objectives must be maximized, all of the components of the normalized target vector were equal to 100 . The modelling and optimization tasks were performed by using the GAMS programming language (The General Algebraic Modeling System), the CONOPT solver being selected. 


\subsection{Model Validation: Determining the Number of Cells from a Reference System}

Before the validation of the model developed in this work, an internal parameter that determines the performance of the model must be defined: the number of cells to comprise each membrane fiber, taking a reference system. Figure 2 shows the evolution of the recovery of $\mathrm{O}_{2}$ (permeate) and the corresponding purity for the separation of air with fibers made of cellulose acetate as function of the number of cells considered in the model [40].

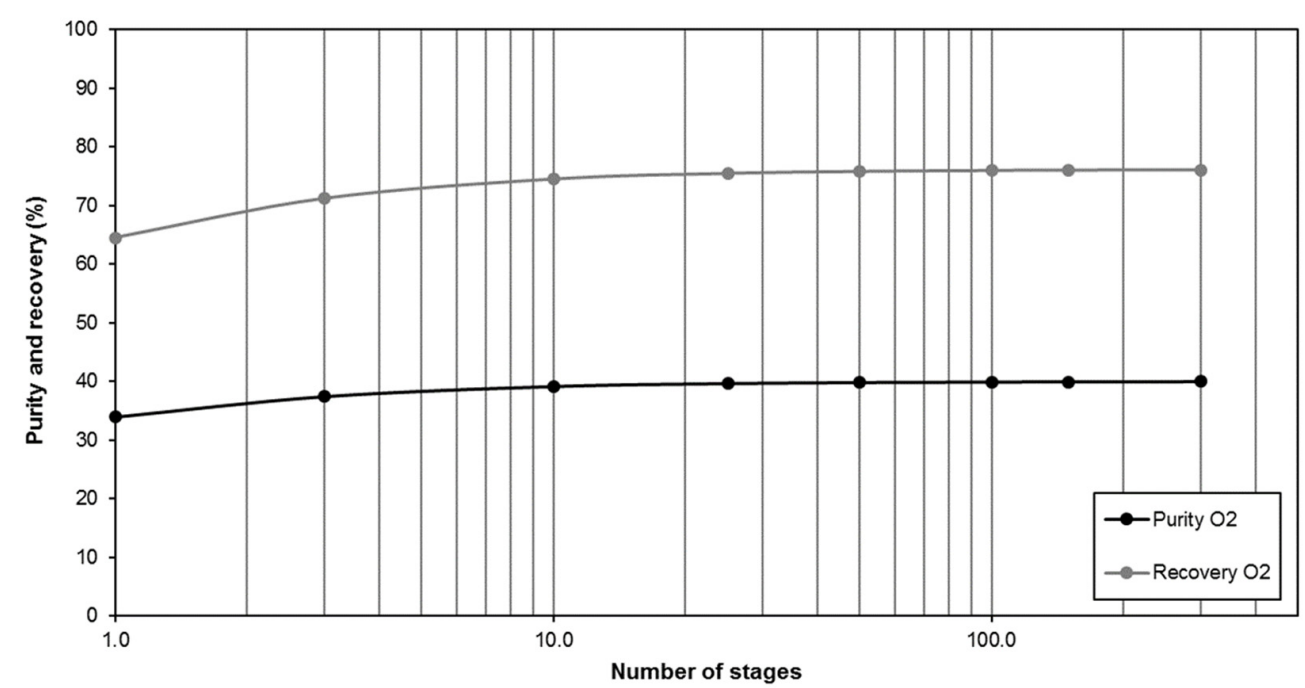

Figure 2. Evolution of the recovery and purity of $\mathrm{O}_{2}$ (permeate) as function of the modelled number of cells considered in the membrane module.

The selection of the number of cells must take into account the balance between the precision of the model and its calculation load. On the one hand, when a low number of cells was chosen, the corresponding calculation load is light and the model can be run fast, but the obtained result can be imprecise and inadequate in representing the system. As an example, if the design selected 10 cells, the number of equations required was 321 , with 882 non-zero elements in the model. On the other hand, a high number of cells can obtain much more precise results, but at the expense of heavy calculation loads. For instance, the consideration of 300 cells increased the number of equations to 9891 , and 27,562 non-zero elements were included in the model. Under these higher load conditions, the model obtained a $40.0 \%$ purity and $76.1 \%$ recovery, whereas the corresponding values in the case of 10 cells were $39.2 \%$ and $74.5 \%$, respectively (the underestimation of the parameters was above $2 \%$ in both cases). The selection of 100 cells was preferred in this work, as it provides an adequate compromise between the model load (3291 equations and 9162 non-zero elements) and its precision (underestimation not higher than $0.15 \%$ when compared to the selection of 300 cells).

In order to validate the developed mathematical model, the values predicted by the model were compared to experimental data previously published for air separation employing cellulose-acetate-based asymmetric hollow fibers [40]. Figure 3 presents the experimental and calculated $\mathrm{O}_{2}$ and $\mathrm{N}_{2}$ molar fractions in the obtained permeate and retentate streams, respectively, as a function of the stage cut (which correlates the feed and retentate streams through the total membrane area available for permeation) for the bore-side feed countercurrent flow conditions. 


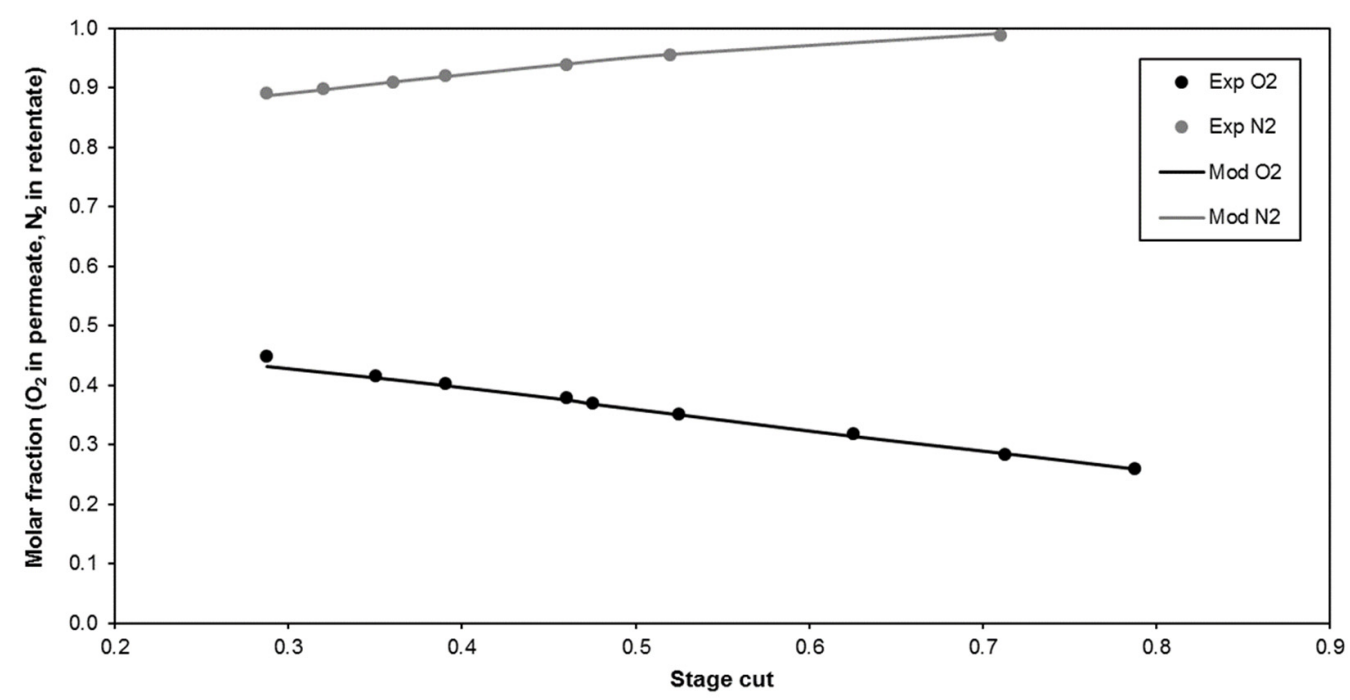

Figure 3. Experimental and calculated $\mathrm{O}_{2}$ and $\mathrm{N}_{2}$ molar fractions in the obtained permeate and retentate streams, respectively, as a function of stage cut.

The agreement between the experimental data and the modeled predictions is satisfactory. The $\mathrm{R}^{2}$ values of the correlation lines between the concentrations obtained from the model and the experimental ones were 0.993 and 0.998 for $\mathrm{O}_{2}$ and $\mathrm{N}_{2}$, respectively. The comparative analysis of the results revealed that the model underestimated the productivity of the membrane, with modeled $\mathrm{O}_{2}$ concentrations slightly lower than the experimental ones (below $2 \%$ in average), especially for the lowest stage cut values. Therefore, this case was not subjected to the overestimation of the membrane productivity that was previously reported by some authors when the pressure losses of the lumen side of the membrane were not considered [31].

\section{Case Study to Optimize: Separation of $\mathrm{CO}_{2} / \mathrm{CH}_{4}$ with Both Components as Targets}

This study is focused on the estimation of the potential of different non-commercial membranes for the separation of $\mathrm{CO}_{2} / \mathrm{CH}_{4}$, working with two types of highly $\mathrm{CO}_{2}$ permeable membranes whose selective layers possess different hydrophobic and hydrophilic characteristics. These membranes may be employed for different applications where the separation of both gases is required, such as biogas upgrading, natural gas sweetening or enhanced oil recovery $[31,32,41]$. The study of the technical performance of the selected membranes can provide a better understanding of their potentiality.

The two types of membranes selected for this study were: (i) a modified commercial hydrophobic membrane with a polydimethylsiloxane (PDMS) top layer (DeltaMem AG, $\mathrm{CH}$-Allschwil) and (ii) a hydrophilic flat sheet composite membrane with a hydrophilic ionic liquid-chitosan (IL-CS) thin layer on a commercial polyethersulfone (PES) support developed in our laboratory. The chitosan biopolymer (CS matrix hybridized with 1-ethyl3-methylimidazolium acetate ([emim][ac]) ionic liquid (IL) as filler) was coated on the polyethersulfone (PES) support, as the surface modification of robust supports provided the option of tuning up the membrane separation properties and decreasing the probability of defects when the thickness of the membranes was significantly reduced. Both membranes were immersed in $\mathrm{NaOH} 1 \mathrm{M}$ solutions and washed thoroughly before characterization. The $\mathrm{NaOH}$ treatment was used to enhance the affinity towards acid gas molecules, such as $\mathrm{CO}_{2}$, contributing to increasing the $\mathrm{CO}_{2}$ separation properties from other gases and, therefore, leading to a higher selectivity.

These membranes were selected due to their promising permeance and selectivity parameters among different flat sheet dense and thin film composite membranes after gas permeation experiments covering the gas mixtures $\mathrm{CO}_{2} / \mathrm{N}_{2}$ and $\mathrm{CO}_{2} / \mathrm{CH}_{4}$ carried out in previous studies of the research group [24,28,42]. The configurations of the polymeric dense layer on a porous support in the type of thin film composite membrane, flat-sheet or hollow 
fiber, were considered, as multilayer composite membranes also offer the possibility to optimize membrane layer materials independently, allowing for the transfer of the selective layer properties to different geometries that could be more easily implemented at a large scale.

The membranes used for this study are flat-sheet composite membranes, the commercial PERVAP 4060 (DeltaMem AG, CH-Allschwil) with a 1-1.5 $\mu$ m thick PDMS top layer and a total thickness of $180 \mu \mathrm{m}$, which was modified by a $\mathrm{NaOH}$ treatment, and a self-prepared hydrophilic IL-CS/PES composite membrane fabricated in our laboratory with a similar selective layer thickness and the same $\mathrm{NaOH}$ treatment as the commercial hydrophobic membrane. The performance parameters were obtained from gas permeation experiments, in a laboratory stainless-steel cell, which provided an effective membrane area of $15.6 \mathrm{~cm}^{2}$, operating at $298 \mathrm{~K}$ and a feed pressure of $2 \mathrm{~atm}$ (pressure ratio 4).

The permeance and selectivity parameters for the two types of membranes are compiled in Table 1. The performance of these membranes in terms of the Robeson's upper bound, as a useful screening tool for the development or innovation in membrane materials, and the surface characterization studies by ATR-FTIR, were also reported elsewhere [24], the $\mathrm{NaOH}$ treatment being particularly remarkable in attracting $\mathrm{CO}_{2}$ preferentially. These data sets are required for the evaluation of the process performance, focusing on the tasks of (i) membrane system modelling (flow patterns), (ii) sensitivity analysis in the simulation of a single stage process, multistage or hybrid configurations and (iii) process optimization objectives of the product quality (given in terms of purity and recovery variables), as well as the separation process costs. The permeance of the most permeable component $\left(\mathrm{CO}_{2}\right.$ in this case) in GPU (1 GPU $\left.=10^{-6} \mathrm{~cm}^{3}(\mathrm{STP}) \mathrm{cm}^{-2} \mathrm{~s}^{-1} \mathrm{cmHg}^{-1}\right)$ was defined as the pressure-normalized flux of the gas component through a membrane. The selectivity was calculated as the ratio between the permeance of the fast and slow gas components in a gas pair; in the case of this work, $\mathrm{CO}_{2}$ and $\mathrm{CH}_{4}$, respectively.

Table 1. Characterization in terms of permeance and selectivity of the selected membranes for the $\mathrm{CO}_{2} / \mathrm{CH}_{4}$ separation process. Test type: single gas experiments, laboratory cell, pressure $=2 \mathrm{~atm}$, temperature $=298 \mathrm{~K}$.

\begin{tabular}{cccc}
\hline Membrane & $\begin{array}{c}\mathrm{CO}_{2} \text { Permeance } \\
\text { (GPU) }\end{array}$ & $\begin{array}{c}\mathrm{CO}_{2} / \mathrm{CH}_{4} \text { Selectivity } \\
(-)\end{array}$ & Reference \\
\hline PDMS (commercial) & 266 & 3.1 & {$[24]$} \\
PDMSt (modified) & 73.7 & 10.7 & {$[24]$} \\
IL1 (IL-CS & 8.5 & 2.7 & {$[28,42]$} \\
self-standing) & 102 & 54.8 & {$[28,42]$} \\
IL2 (IL-CS/PES) & & & \\
\hline
\end{tabular}

From the data included in Table 1, it can be pointed out that (i) the $\mathrm{CO}_{2} / \mathrm{CH}_{4}$ separation factor of the commercial PDMS membrane was increased by the $\mathrm{NaOH}$ treatment (from single and mixed gases permeation experiments) and (ii) the hydrophobic PDMS membrane showed a lower $\mathrm{CO}_{2} / \mathrm{CH}_{4}$ selectivity than the improved hydrophilic IL-CS/PES composite membrane (IL 2), considering this fact as key for the selection of this type of membrane to achieve the product quality targets in further implementation, contributing to providing highly $\mathrm{CO}_{2}$-permeable and thermally robust polymers.

\section{Results and Discussion}

\subsection{Module Simulation}

The developed model was applied to the comparison of the performance of the four membranes selected as the case study. These $\mathrm{CO}_{2} / \mathrm{CH}_{4}$-selective membranes can be employed for different application where the separation of both gases is required, such as biogas upgrading, natural gas sweetening or enhanced oil recovery. The study of the technical performance of hollow fiber modules made of the selected membranes can provide a better understanding of their potentiality. The influence of the main design 
and operation variables (applied pressures and stage cut) on the simulated modules was studied by means of a sensitivity analysis. The scale of the process was fixed to provide enough of a membrane area to treat a feed flowrate of $1 \mathrm{~m}^{3} / \mathrm{h}$ (STP) with an initial molar composition of $35 \% \mathrm{CO}_{2}$ and $65 \% \mathrm{CH}_{4}$. The influence of varying the feed pressure in the range from 2 to $10 \mathrm{~atm}$ (permeate side at atmospheric pressure) while keeping the stage cut constant at 0.5 over the purities and recoveries is graphed in Figure 5.

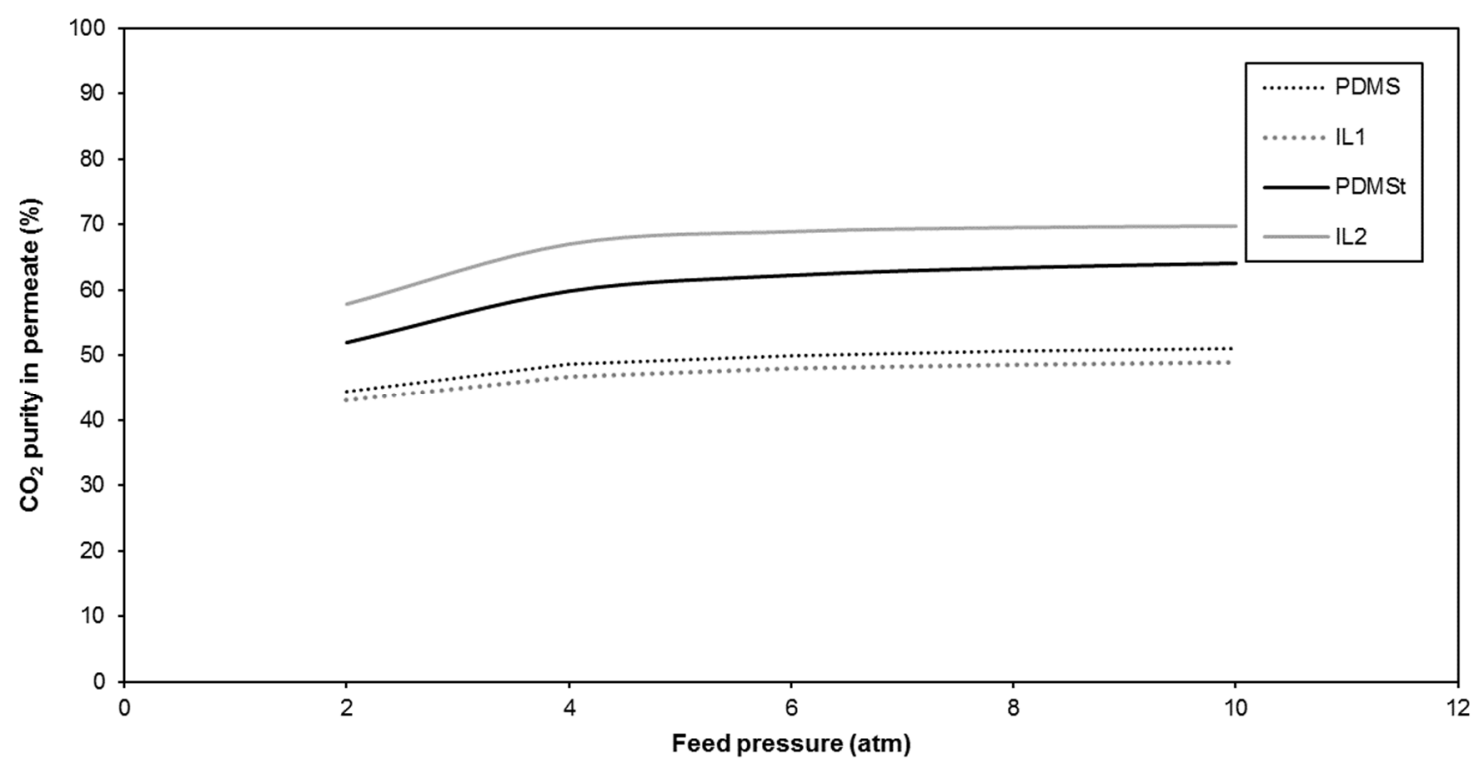

(a)

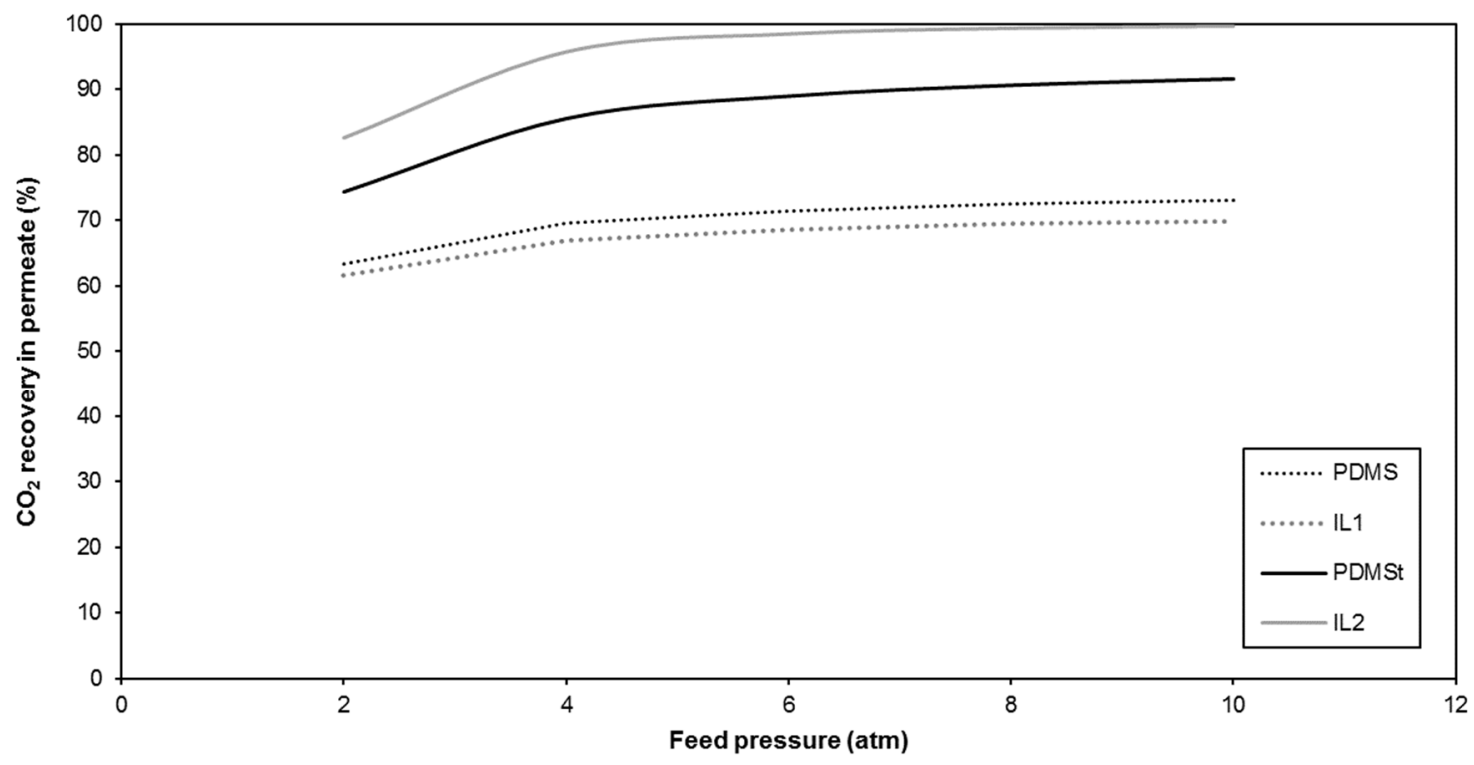

(b)

Figure 4. Cont. 


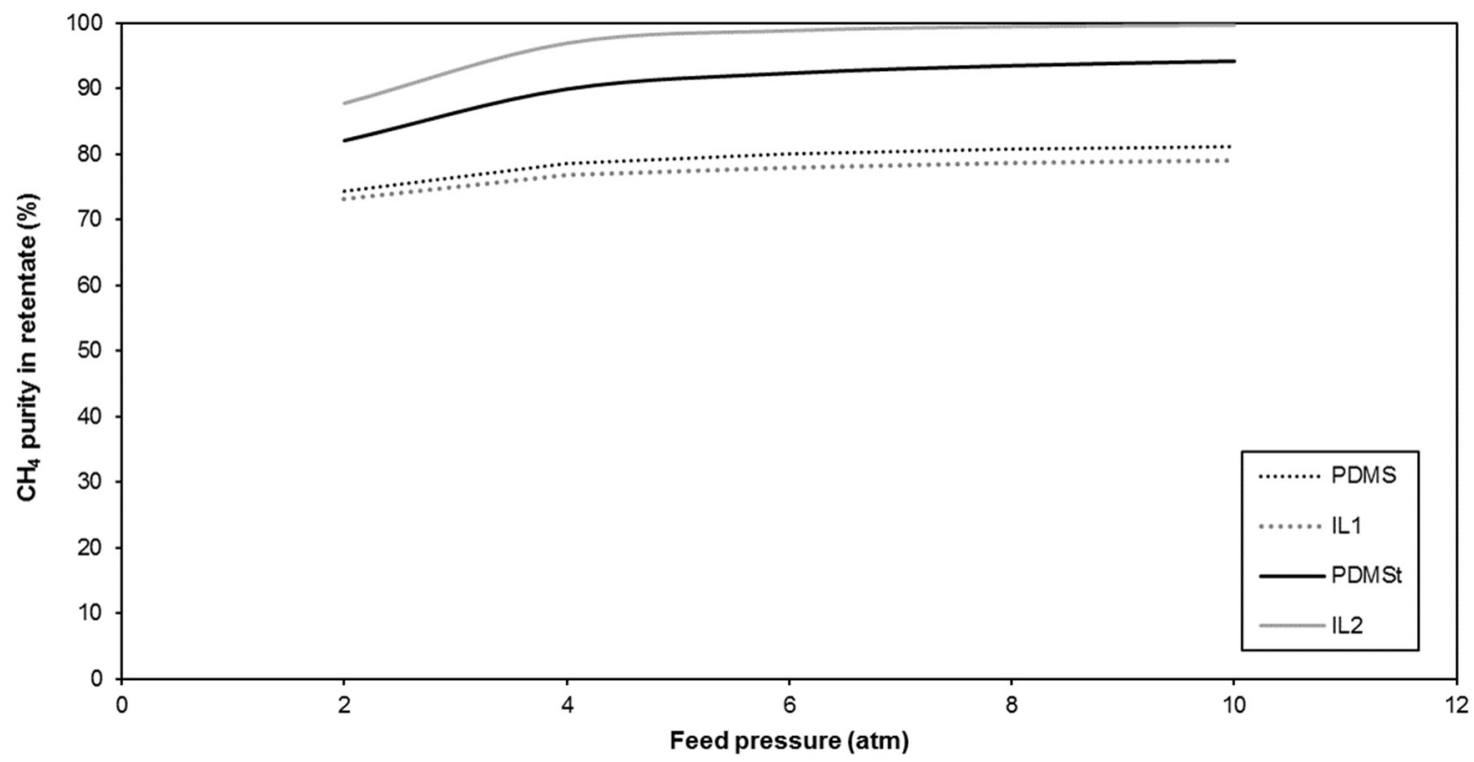

(c)

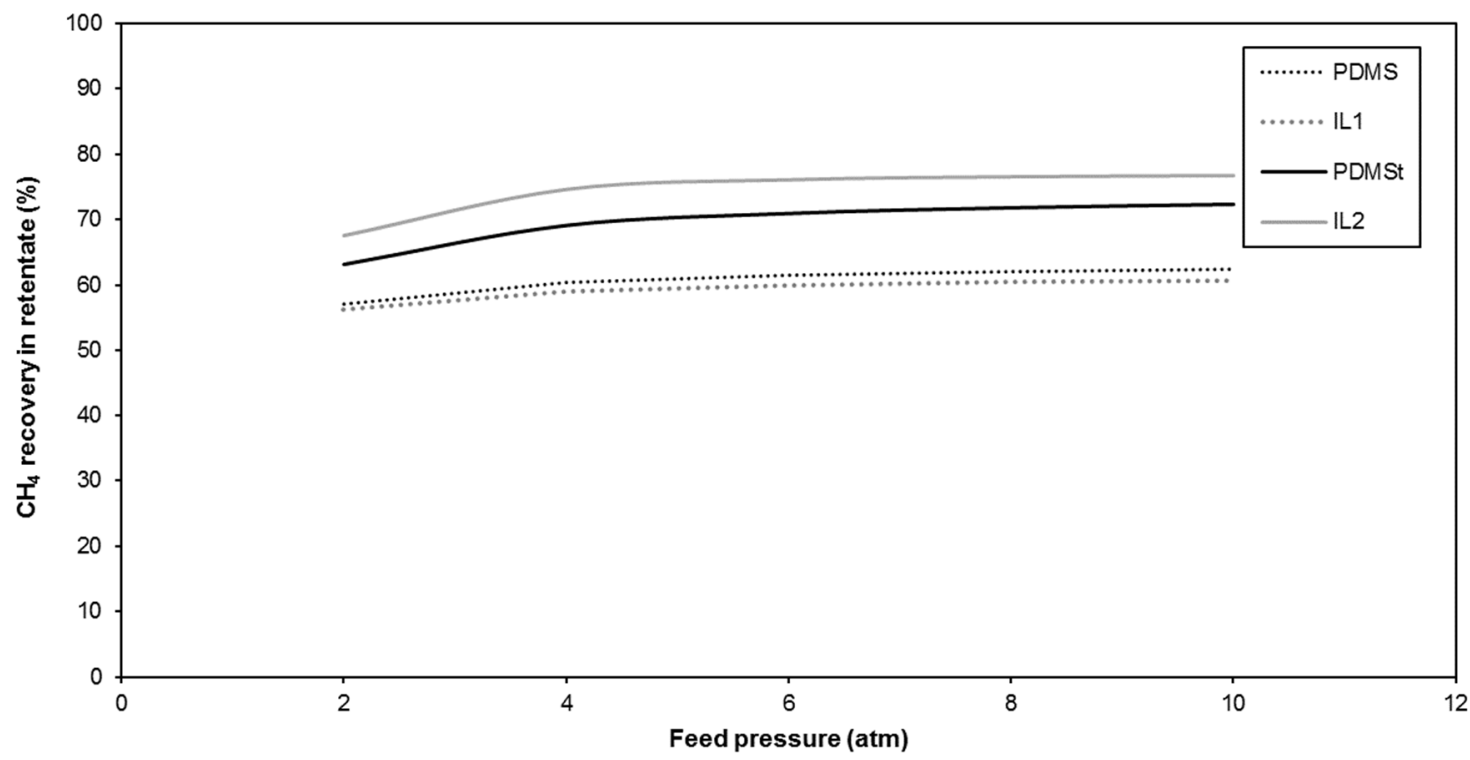

(d)

Figure 4. Influence of the feed pressure on (a) $\mathrm{CO}_{2}$ purity, (b) $\mathrm{CO}_{2}$ recovery, (c) $\mathrm{CH}_{4}$ purity and (d) $\mathrm{CH}_{4}$ recovery for the different membranes $\left(\mathrm{P}_{\mathrm{Q}}=1 \mathrm{~atm}\right.$, stage $\mathrm{cut}=0.5, \mathrm{CO}_{2} / \mathrm{CH}_{4}$ feed composition $\left.=0.35 / 0.65\right)$.

The results revealed the expected trend: the higher the feed pressure, the higher the recoveries and purities for both gases. All of the membranes took advantage of high pressures, but the most important increment corresponded to the membrane that showed the best performance: the IL2 membrane. It was able to achieve a $69.8 \% \mathrm{CO}_{2}$ purity with practical total recovery (greater than $99.7 \%$ ) and losses of $\mathrm{CH}_{4}$ in the permeate below $25 \%$, working at $10 \mathrm{~atm}$. On the contrary, IL1 was the membrane that exhibited the worst performance. Under maximal pressure operation conditions, the achieved percentage of $\mathrm{CO}_{2}$ purity was $49.0 \%$ and the corresponding recovery was below $70 \%$. The PDMS membrane was just slightly better than the IL1 membrane, whereas the PDMSt membrane showed a performance more similar to the IL2 membrane. Therefore, once again, the effectiveness of the followed treatment of the virgin membrane was confirmed. Nevertheless, for all of the membranes, the purities and recovery trend to attain chateau 
values and the increment in the feed pressure did not imply a relevant increase in the performance parameters. Although the purities and recoveries did not rise significantly once a critical feed pressure was achieved, another advantage of the implementation of high pressures even above these critical vales was the reduction in the membrane required to obtain a fixed stage cut. Once the ratio of the feed pressure to permeate pressure was fixed (which assured that the performance parameters were maintained constant, as shown in Table 2), the membrane area required was directly proportional to the feed pressure, and the membrane could be reduced by half just by doubling the feed pressure. Taking this into account, the use of a vacuum in the permeate side of the membrane to allow the feed at atmospheric pressure implies an increased membrane area, which can be difficult to compensate by the savings due to the avoided feed pressurization [43].

Table 2. Process performance parameters of the IL2 membrane under different pressure conditions $\left(1 \mathrm{~m}^{3} / \mathrm{h}(\mathrm{STP})\right.$ feed stream with $\mathrm{CO}_{2} / \mathrm{CH}_{4}$ composition $\left.=0.35 / 0.65\right)$.

\begin{tabular}{cccc}
\hline $\begin{array}{c}\text { Pressure Ratio } \\
\left(\mathbf{P}_{\mathrm{F}} / \mathbf{P}_{\mathbf{Q}}\right)\end{array}$ & $\mathbf{2 . 0 / 0 . 5}$ & $\mathbf{4 . 0 / 1 . 0}$ & $\mathbf{8 . 0 / 2 . 0}$ \\
\hline $\mathrm{CO}_{2}$ purity $(\%)$ & & 67.0 & \\
$\mathrm{CO}_{2}$ recovery $(\%)$ & 95.8 & \\
$\mathrm{CH}_{4}$ purity $(\%)$ & & 97.0 & \\
$\mathrm{CH}_{4}$ recovery $(\%)$ & & 74.6 & \\
Membrane area $\left(\mathrm{m}^{2}\right)$ & 167.6 & 83.8 & 41.9 \\
\hline
\end{tabular}

In a similar way, the stage cut was modified in the range from 0.2 to 0.8 to evaluate the evolution of the module performance, while the feed pressure was fixed at 4 atm (retentate side at atmospheric pressure). The obtained results can be observed in Figure 5. In this case, the contradictory effects of increasing the stage cut must be highlighted. On the one hand, high stage cut values implied a higher membrane area, which promoted the permeation of $\mathrm{CO}_{2}$ to the permeate stream and the achievement of high $\mathrm{CO}_{2}$ recovery values. For example, a total recovery of $\mathrm{CO}_{2}$ (corresponding recovery value above $99.9 \%$ ) was obtained when a 0.80 stage cut was applied to the PDMSt membrane or 0.65 stage cut in the case of the IL2 membrane. The other two membranes (PDMS and IL1) attained $\mathrm{CO}_{2}$ recovery values of around $95 \%$ for the maximal considered stage cut. Moreover, these high recovery values corresponded to the high purity of the $\mathrm{CH}_{4}$ retentate stream (just pure $\mathrm{CH}_{4}$ when total $\mathrm{CO}_{2}$ recovery was possible and values around 90\% for the PDMS and IL1 membranes). However, on the other hand, as a consequence of the great amount of gas permeated, the purity of the $\mathrm{CO}_{2}$ permeate stream was low for high stage cut values. At the maximal stage cut value (0.80), the $\mathrm{CO}_{2}$ purity values ranged from $41.1 \%$ for the IL1 membrane to $43.8 \%$ for the IL2 membrane. This fact corresponded to unaffordable losses of $\mathrm{CH}_{4}$ in the permeate stream, with recovery values for this gas in the range of $27.5-30.8 \%$. These results gave a clear idea about the balance between the different objectives for the technical optimization of the separation process based on these types of membrane modules.

Finally, the sensitivity analysis investigated the performance of the membrane modules under different compositions of the feed stream, in the range from a 0.2 to 0.8 molar fraction of $\mathrm{CO}_{2}$, with a feed pressure of $4 \mathrm{~atm}$ and a constant stage cut equal to 0.5 . Once again, as in the case of the stage cut, opposing effects appeared (Figure 6). Whereas the selection of enriched $\mathrm{CO}_{2}$ feed streams favored the production of high-purity $\mathrm{CO}_{2}$ permeate, the corresponding $\mathrm{CO}_{2}$ recoveries decreased, since more $\mathrm{CO}_{2}$ escaped from the module in the retentate stream. The opposite situation occurred in the case of $\mathrm{CH}_{4}$ : the treatment of $\mathrm{CO}_{2}$-rich streams implied a low purity of $\mathrm{CH}_{4}$ in the retentate stream, but with high recovery values (reduced losses of this gas to the permeate stream) [44]. For example, the IL2 membrane was able to attain a $96.6 \% \mathrm{CO}_{2}$ purity from the initial 0.65 molar fraction, whereas the IL1 achieved a $76.6 \%$ purity, but the corresponding $\mathrm{CH}_{4}$ purities were $66.6 \%$ and $46.6 \%$, respectively. 


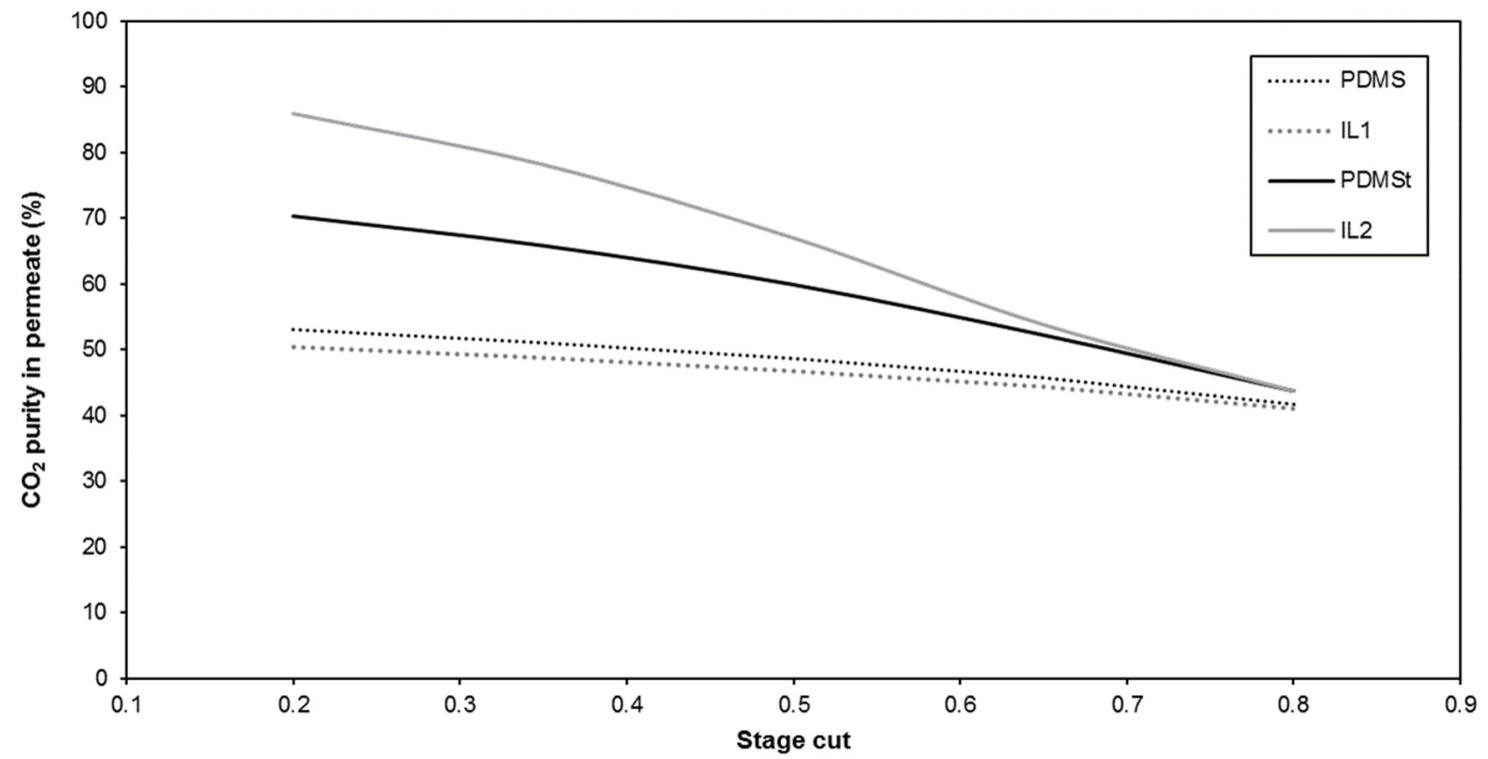

(a)

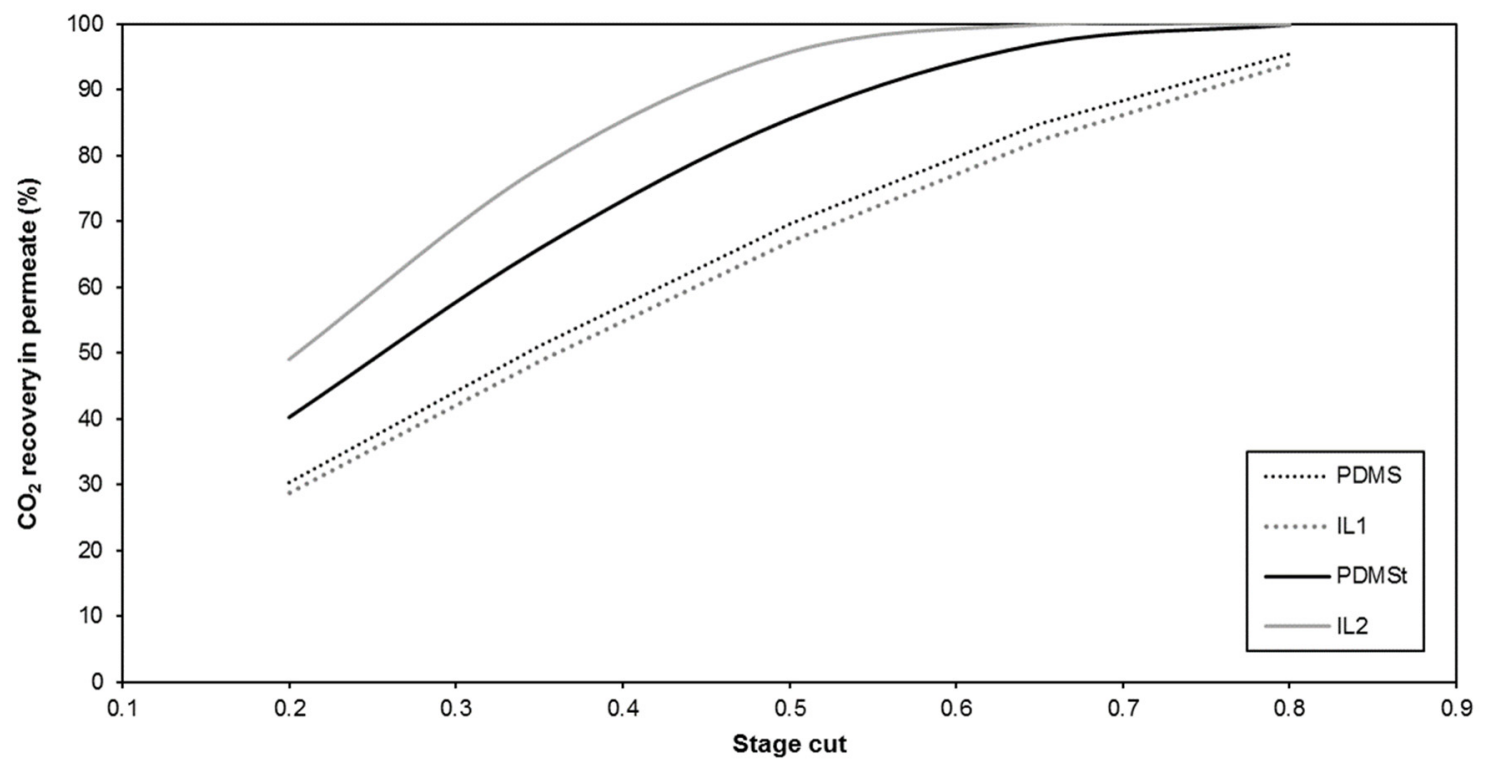

(b)

Figure 5. Cont. 


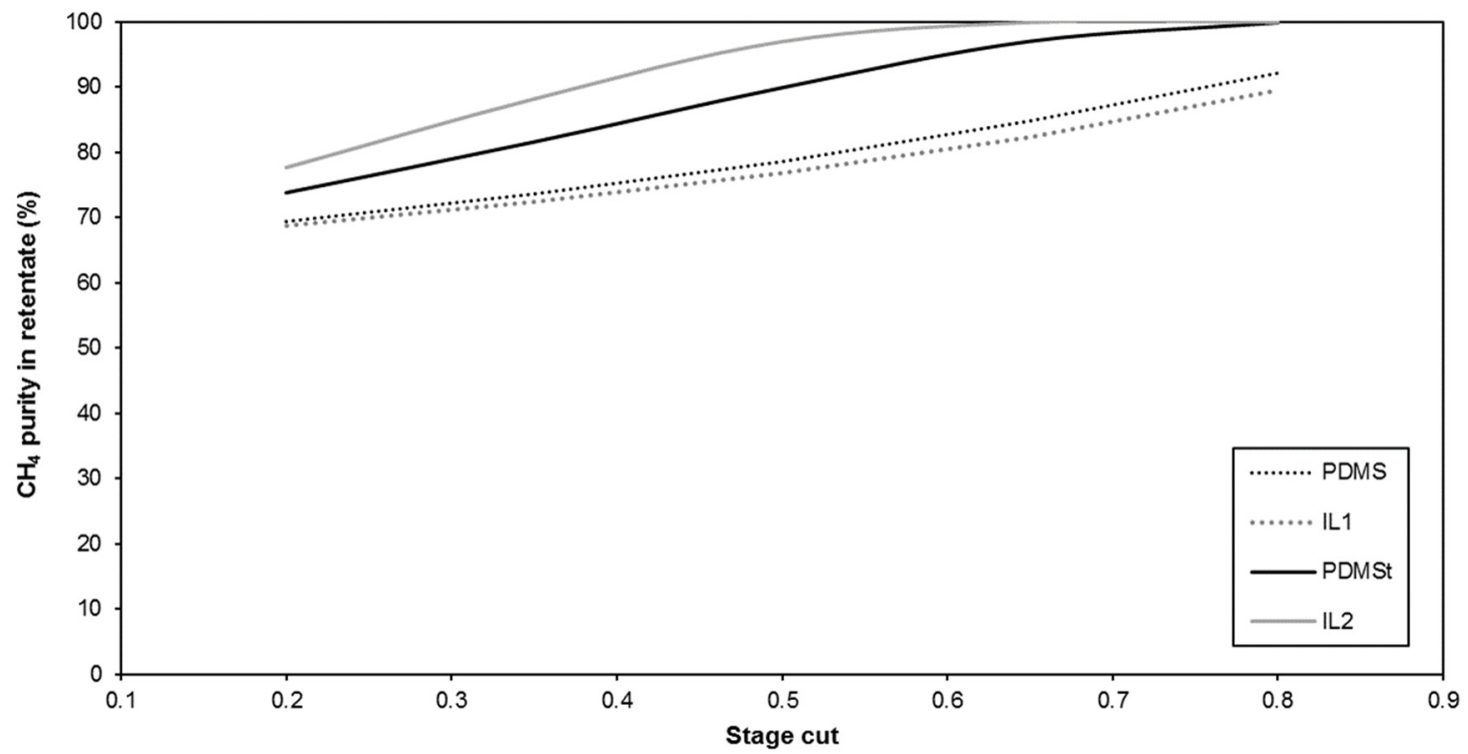

(c)

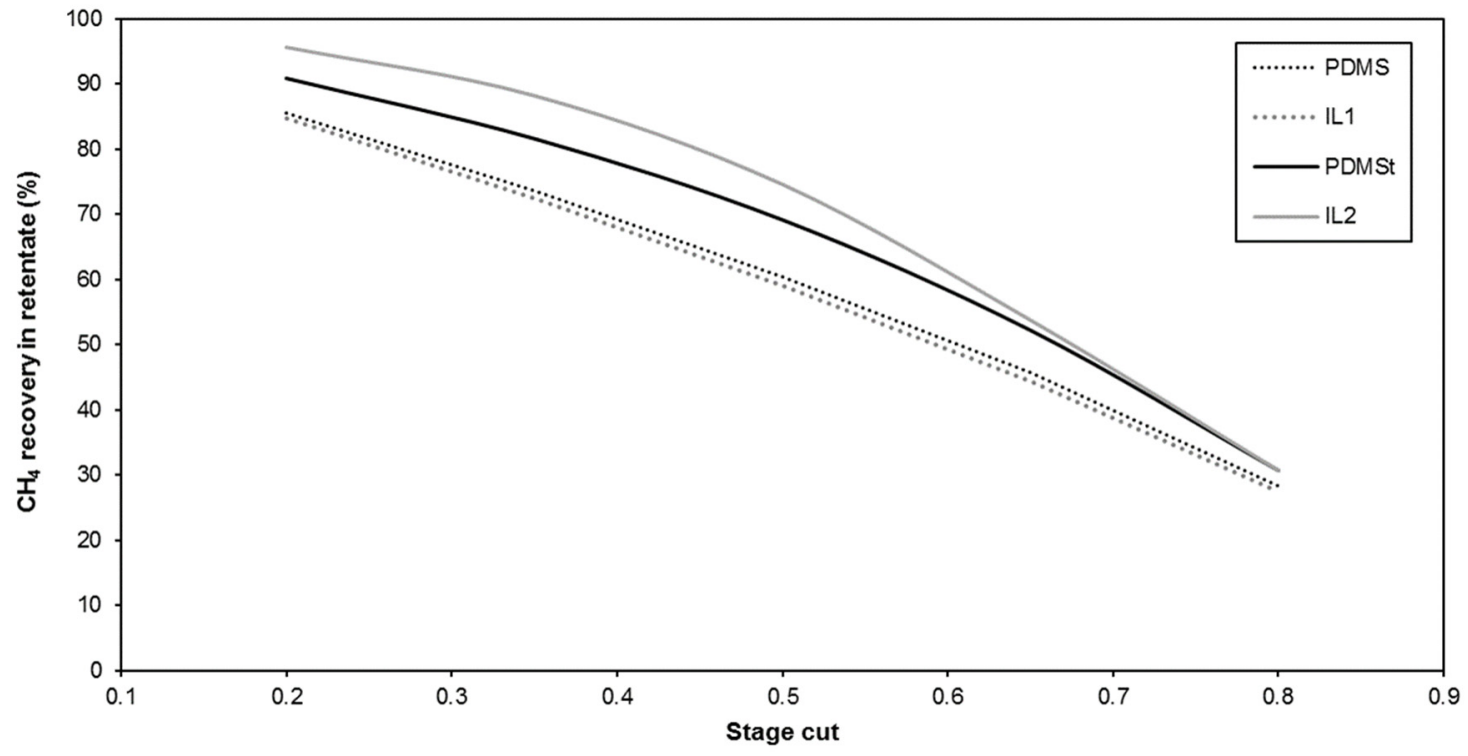

(d)

Figure 5. Influence of the stage cut on (a) $\mathrm{CO}_{2}$ purity, (b) $\mathrm{CO}_{2}$ recovery, (c) $\mathrm{CH}_{4}$ purity and (d) $\mathrm{CH}_{4}$ recovery for the different membranes $\left(\mathrm{P}_{\mathrm{F}}=4 \mathrm{~atm}, \mathrm{P}_{\mathrm{Q}}=1 \mathrm{~atm}, \mathrm{CO}_{2} / \mathrm{CH}_{4}\right.$ feed composition $\left.=0.35 / 0.65\right)$. 


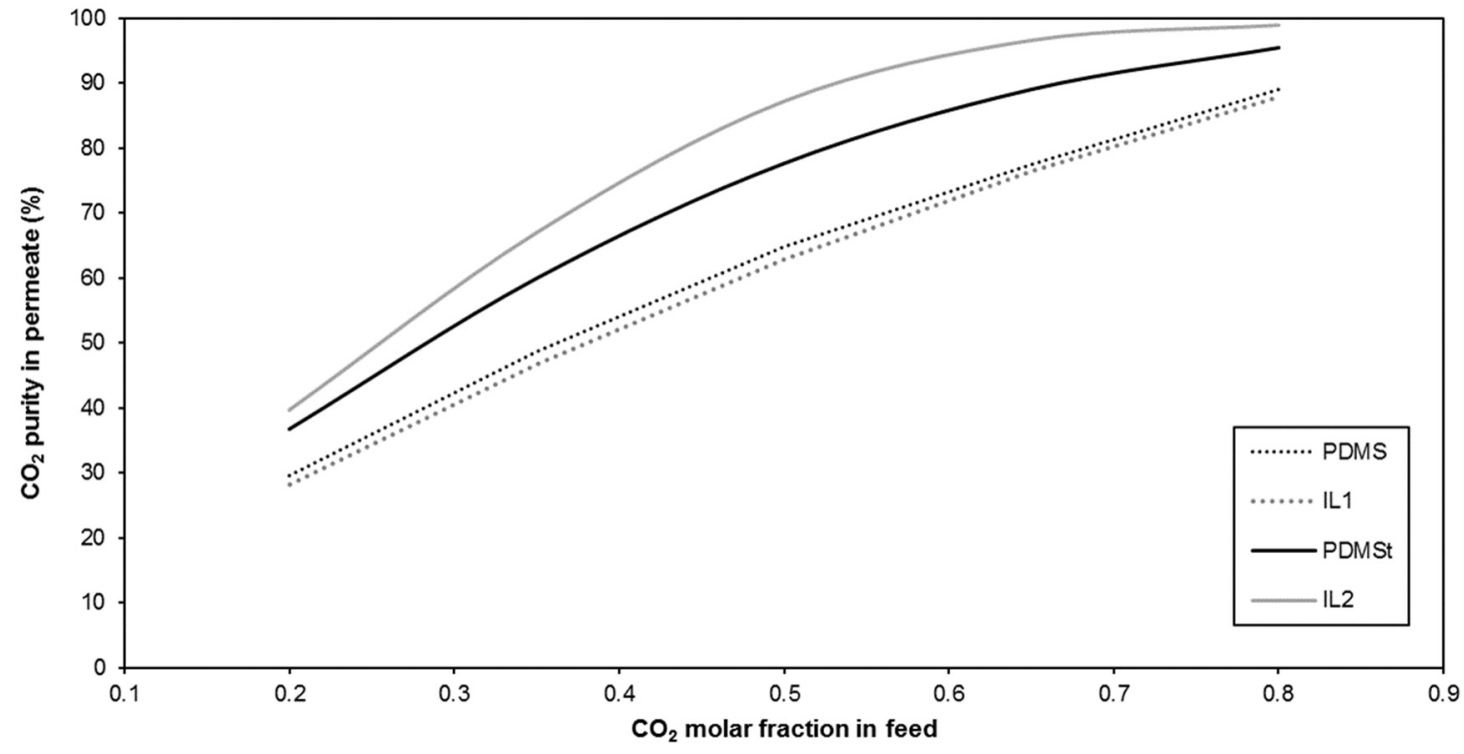

(a)

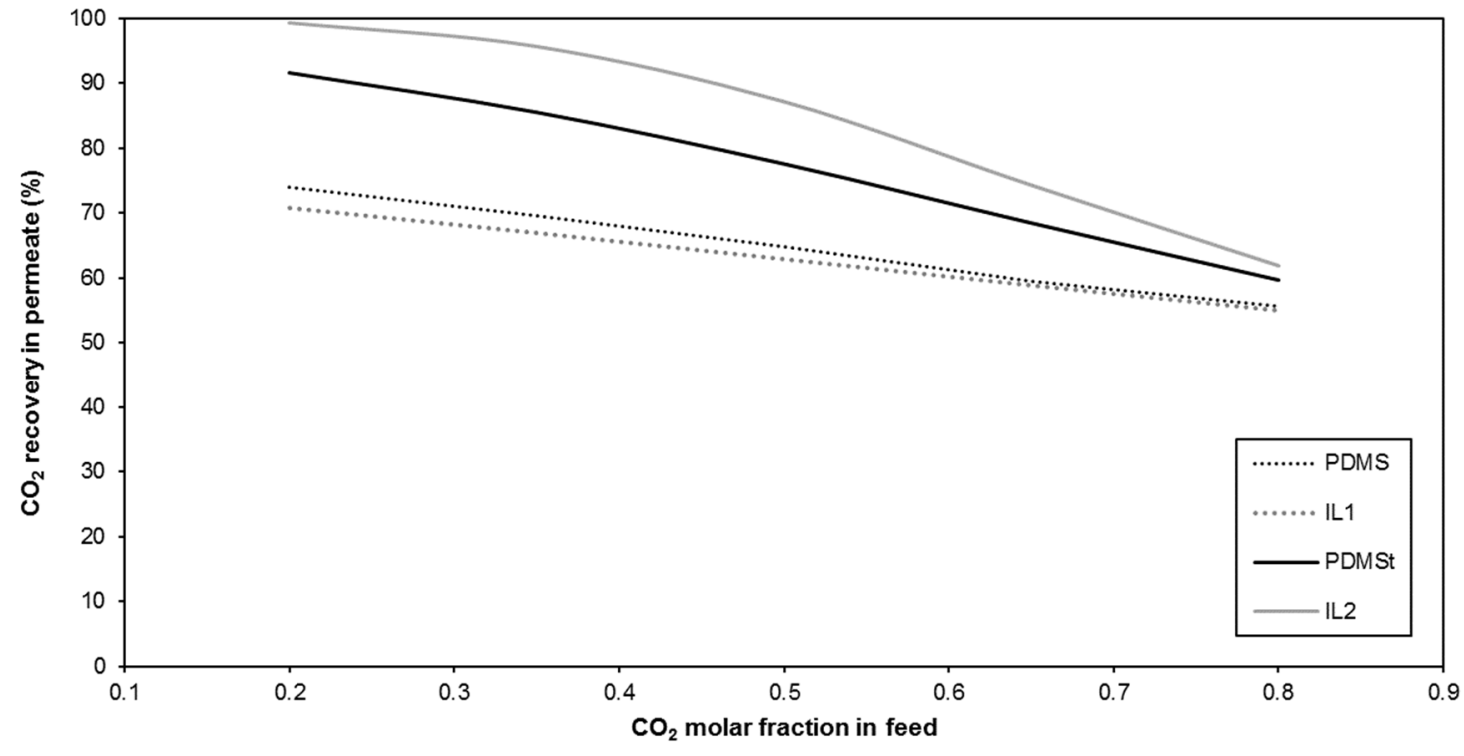

(b)

Figure 6. Cont. 


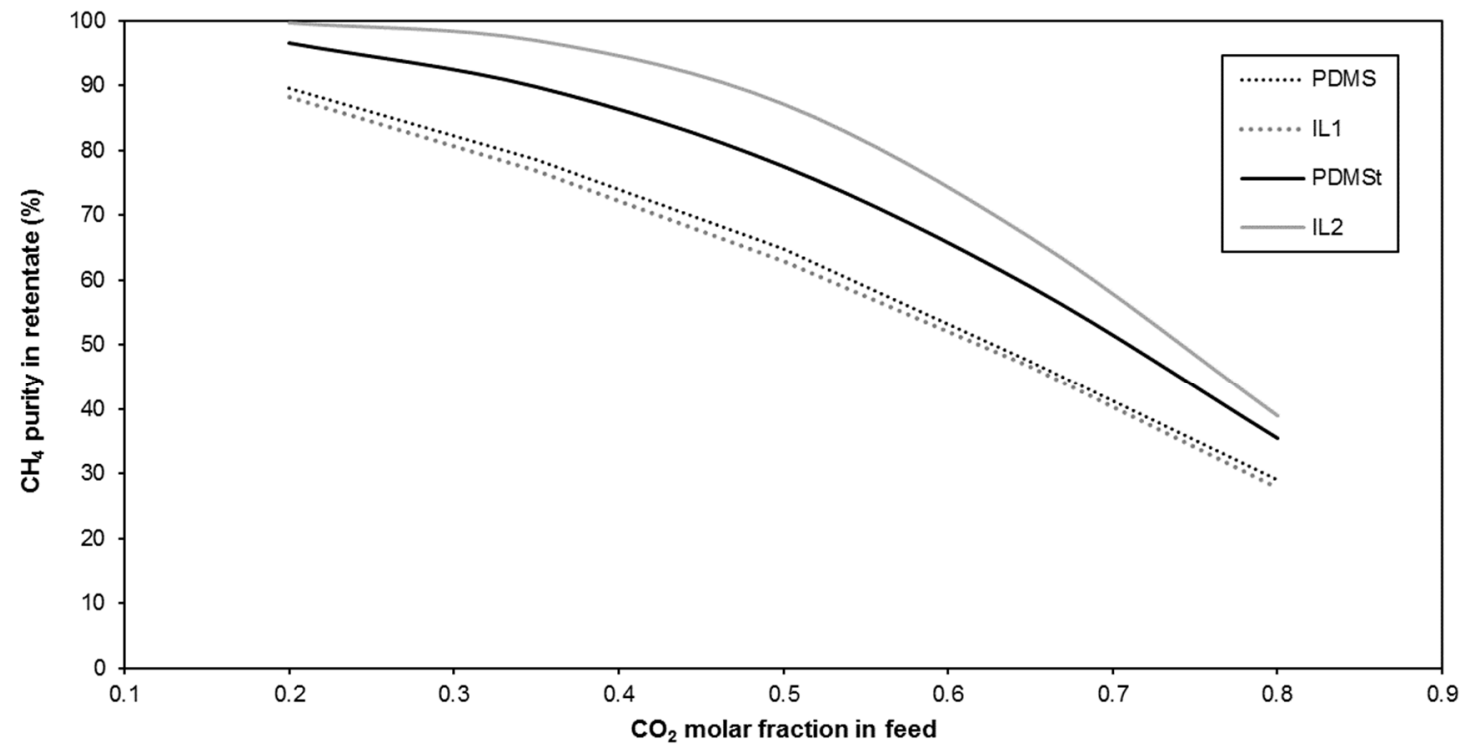

(c)

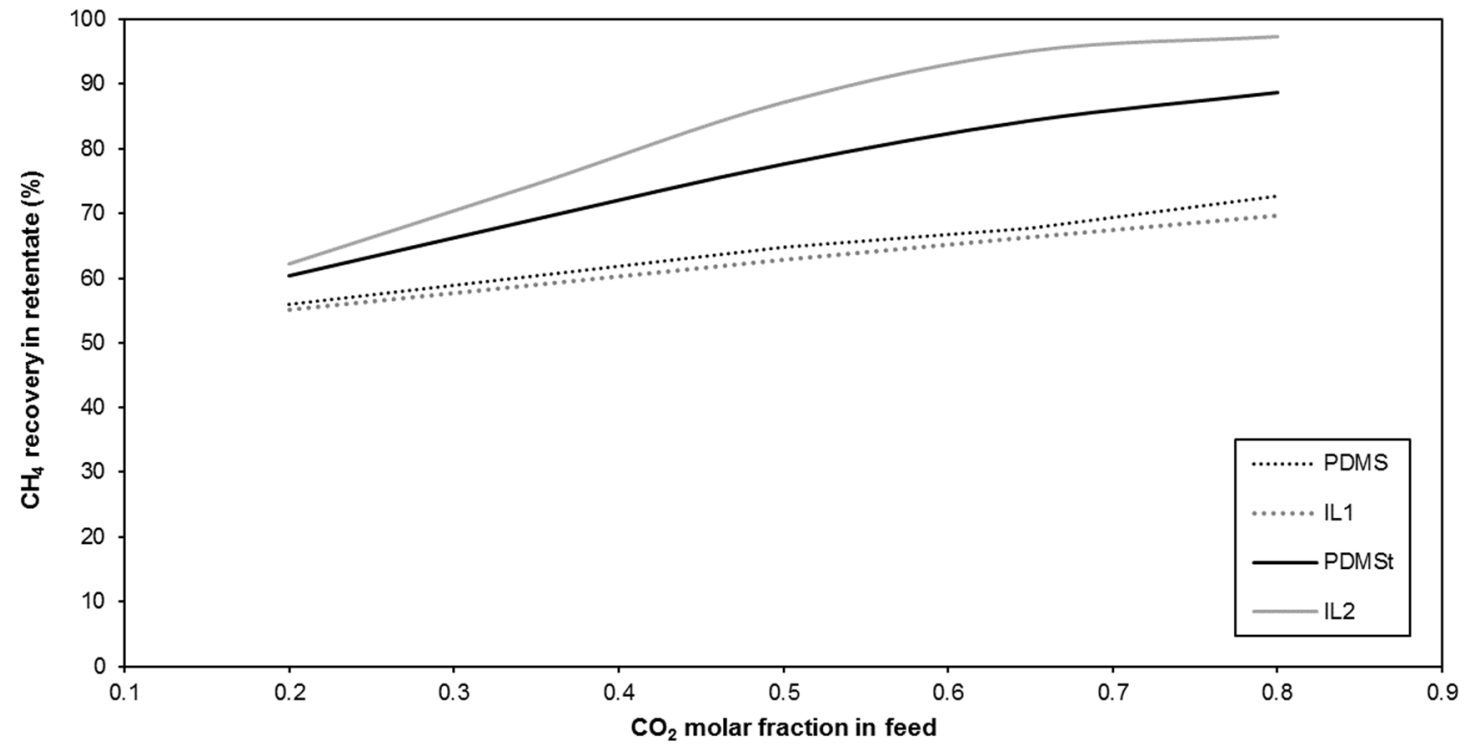

(d)

Figure 6. Influence of the feed $\mathrm{CO}_{2}$ molar fraction on (a) $\mathrm{CO}_{2}$ purity, (b) $\mathrm{CO}_{2}$ recovery, (c) $\mathrm{CH}_{4}$ purity and (d) $\mathrm{CH}_{4}$ recovery for the different membranes $\left(\mathrm{P}_{\mathrm{F}}=4 \mathrm{~atm}, \mathrm{P}_{\mathrm{Q}}=1 \mathrm{~atm}\right.$, stage cut $\left.=0.5\right)$.

\subsection{Module Optimization}

The sensitivity analysis provided a clearer idea about the influence of the main design and operation variables of the membrane modules. It could be considered as a previous step to the optimization covered in this section. The results of the optimization of the PDMS, PDMSt and IL2 membranes are compiled in Tables 3 and 4 for the vacuum permeate (0.2 atm) and pressurized feed (20 atm), respectively. 
Table 3. Process performance parameters under optimal conditions (considering different objectives) of the PDMS, PDMSt and IL2 membranes (vacuum permeate at $0.2 \mathrm{~atm}$ ).

\begin{tabular}{|c|c|c|c|c|c|c|c|c|c|c|c|c|c|}
\hline \multirow[b]{2}{*}{ Membrane } & \multicolumn{4}{|c|}{ Objectives } & \multicolumn{4}{|c|}{ Values } & \multirow{2}{*}{$\begin{array}{l}\text { Stage } \\
\text { Cut }\end{array}$} & \multirow{2}{*}{$\underset{(\text { atm) }}{\mathbf{P}_{\mathrm{F}}}$} & \multirow{2}{*}{$\underset{(\mathrm{atm})}{\mathrm{P}_{\mathrm{Q}}}$} & \multirow{2}{*}{$\begin{array}{l}\text { Area } \\
\left(\mathrm{m}^{2}\right)\end{array}$} & \multirow[b]{2}{*}{$D_{N}$} \\
\hline & $\begin{array}{c}\mathrm{CO}_{2} \\
\text { Purity }\end{array}$ & $\begin{array}{c}\mathrm{CO}_{2} \\
\text { Recovery }\end{array}$ & $\begin{array}{c}\mathrm{CH}_{4} \\
\text { Purity }\end{array}$ & $\begin{array}{c}\mathrm{CH}_{4} \\
\text { Recovery }\end{array}$ & $\begin{array}{c}\mathrm{CO}_{2} \\
\text { Purity }\end{array}$ & $\begin{array}{c}\mathrm{CO}_{2} \\
\text { Recovery }\end{array}$ & $\underset{\text { Purity }}{\mathrm{CH}_{4}}$ & $\begin{array}{c}\mathrm{CH}_{4} \\
\text { Recovery }\end{array}$ & & & & & \\
\hline \multirow{8}{*}{ PDMS } & $x$ & & & & 56.2 & 8.0 & 66.1 & 96.6 & 0.050 & 1.0 & 0.2 & 1.2 & 0.537 \\
\hline & & $X$ & & & 36.8 & 99.9 & 99.2 & 7.6 & 0.950 & 1.0 & 0.2 & 28.7 & 0.560 \\
\hline & $x$ & $x$ & & & 40.5 & 97.9 & 95.3 & 22.5 & 0.846 & 1.0 & 0.2 & 24.7 & 0.489 \\
\hline & & & $x$ & & 36.8 & 99.9 & 99.2 & 7.6 & 0.950 & 1.0 & 0.2 & 28.7 & 0.560 \\
\hline & & & & $X$ & 56.2 & 8.0 & 66.1 & 96.6 & 0.050 & 1.0 & 0.2 & 1.2 & 0.537 \\
\hline & & & $x$ & $x$ & 56.2 & 8.0 & 66.1 & 96.6 & 0.050 & 1.0 & 0.2 & 1.2 & 0.537 \\
\hline & $x$ & $x$ & $x$ & $x$ & 46.2 & 85.9 & 85.8 & 46.2 & 0.650 & 1.0 & 0.2 & 17.9 & 0.393 \\
\hline & & Mini & $1 D_{N}$ & & 49.8 & 69.0 & 78.9 & 62.6 & 0.485 & 1.0 & 0.2 & 12.9 & 0.365 \\
\hline \multirow[t]{8}{*}{ PDMSt } & $x$ & & & & 76.5 & 10.9 & 67.2 & 98.2 & 0.050 & 1.0 & 0.2 & 7.6 & 0.489 \\
\hline & & $x$ & & & 42.2 & $100.0^{*}$ & 100.0 & 26.3 & 0.829 & 1.0 & 0.2 & 253.0 & 0.468 \\
\hline & $x$ & $x$ & & & 56.1 & 95.3 & 96.0 & 59.9 & 0.594 & 1.0 & 0.2 & 144.3 & 0.299 \\
\hline & & & $x$ & & 42.2 & 100.0 & 100.0 * & 26.3 & 0.829 & 1.0 & 0.2 & 253.0 & 0.468 \\
\hline & & & & $X$ & 76.5 & 10.9 & 67.2 & 98.2 & 0.050 & 1.0 & 0.2 & 7.6 & 0.489 \\
\hline & & & $x$ & $X$ & 71.9 & 48.6 & 76.4 & 89.8 & 0.237 & 1.0 & 0.2 & 40.8 & 0.320 \\
\hline & $X$ & $X$ & $X$ & $x$ & 61.0 & 88.4 & 91.7 & 69.6 & 0.507 & 1.0 & 0.2 & 111.9 & 0.257 \\
\hline & \multirow{2}{*}{\multicolumn{4}{|c|}{ Minimal $D_{N}$}} & 64.9 & 79.1 & 87.2 & 77.0 & 0.426 & 1.0 & 0.2 & 86.8 & 0.243 \\
\hline \multirow[t]{8}{*}{ IL2 } & & & & & 92.6 & 13.2 & 68.0 & 99.4 & 0.050 & 1.0 & 0.2 & 8.3 & 0.464 \\
\hline & & $x$ & & & 55.6 & $100.0^{*}$ & 100.0 & 56.9 & 0.630 & 1.0 & 0.2 & 526.6 & 0.310 \\
\hline & \multirow[t]{4}{*}{$x$} & $x$ & & & 73.0 & 94.0 & 96.2 & 81.3 & 0.450 & 1.0 & 0.2 & 234.6 & 0.168 \\
\hline & & & $x$ & & 55.6 & 100.0 & $100.0 *$ & 56.9 & 0.630 & 1.0 & 0.2 & 526.6 & 0.310 \\
\hline & & & & $x$ & 92.6 & 13.2 & 68.0 & 99.4 & 0.050 & 1.0 & 0.2 & 8.3 & 0.464 \\
\hline & & & $x$ & $x$ & 80.5 & 82.7 & 90.5 & 89.2 & 0.360 & 1.0 & 0.2 & 139.0 & 0.149 \\
\hline & $X$ & $x$ & $x$ & $x$ & 76.0 & 90.5 & 94.3 & 84.6 & 0.417 & 1.0 & 0.2 & 194.9 & 0.153 \\
\hline & \multicolumn{4}{|c|}{ Minimal $D_{N}$} & 78.9 & 85.7 & 91.9 & 87.7 & 0.380 & 1.0 & 0.2 & 157.2 & 0.147 \\
\hline
\end{tabular}

* Consideration of minimal area required to achieve complete (greater than $99.99 \%$ ) recovery of $\mathrm{CO}_{2}$.

Table 4. Process performance parameters under optimal conditions (considering different objectives) of the PDMS, PDMSt and IL2 membranes (pressurized feed at $20 \mathrm{~atm}$ ).

\begin{tabular}{|c|c|c|c|c|c|c|c|c|c|c|c|c|c|}
\hline \multirow[b]{2}{*}{ Membrane } & \multicolumn{4}{|c|}{ Objectives } & \multicolumn{4}{|c|}{ Values } & \multirow[b]{2}{*}{$\begin{array}{c}\text { Stage } \\
\text { Cut }\end{array}$} & \multirow{2}{*}{$\underset{\text { (atm) }}{\mathbf{P}_{\mathrm{F}}}$} & \multirow{2}{*}{$\begin{array}{c}P_{Q} \\
\text { (atm) }\end{array}$} & \multirow{2}{*}{$\begin{array}{l}\text { Area } \\
\left(\mathrm{m}^{2}\right)\end{array}$} & \multirow[b]{2}{*}{$D_{N}$} \\
\hline & $\begin{array}{c}\mathrm{CO}_{2} \\
\text { Purity }\end{array}$ & $\begin{array}{c}\mathrm{CO}_{2} \\
\text { Recovery }\end{array}$ & $\underset{\text { Purity }}{\mathrm{CH}_{4}}$ & $\begin{array}{c}\mathrm{CH}_{4} \\
\text { Recovery }\end{array}$ & $\begin{array}{c}\mathrm{CO}_{2} \\
\text { Purity }\end{array}$ & $\begin{array}{c}\mathrm{CO}_{2} \\
\text { Recovery }\end{array}$ & $\underset{\text { Purity }}{\mathrm{CH}_{4}}$ & $\begin{array}{c}\mathrm{CH}_{4} \\
\text { Recovery }\end{array}$ & & & & & \\
\hline \multirow[t]{8}{*}{ PDMS } & $x$ & & & & 60.6 & 8.7 & 66.3 & 97.0 & 0.050 & 20 & 1 & 0.050 & 0.525 \\
\hline & & $X$ & & & 36.8 & 99.9 & 99.6 & 7.7 & 0.950 & 20 & 1 & 1.206 & 0.559 \\
\hline & $x$ & $X$ & & & 42.7 & 97.2 & 95.1 & 29.8 & 0.796 & 20 & 1 & 0.957 & 0.454 \\
\hline & & & $x$ & & 36.8 & 99.9 & 99.6 & 7.7 & 0.950 & 20 & 1 & 1.206 & 0.559 \\
\hline & & & & $X$ & 60.6 & 8.7 & 66.3 & 97.0 & 0.050 & 20 & 1 & 0.050 & 0.525 \\
\hline & & & $x$ & $X$ & 60.6 & 8.7 & 66.3 & 97.0 & 0.050 & 20 & 1 & 0.050 & 0.525 \\
\hline & $X$ & $x$ & $x$ & $X$ & 49.1 & 84.8 & 86.6 & 52.7 & 0.604 & 20 & 1 & 0.681 & 0.362 \\
\hline & & Mini & $1 D_{N}$ & & 52.7 & 70.9 & 80.7 & 65.8 & 0.470 & 20 & 1 & 0.511 & 0.340 \\
\hline \multirow{8}{*}{ PDMSt } & $X$ & & & & 82.8 & 11.8 & 67.5 & 98.7 & 0.050 & 20 & 1 & 0.260 & 0.478 \\
\hline & & $X$ & & & 45.7 & ${ }^{*} 100.0$ & 100.0 & 36.0 & 0.766 & 20 & 1 & 4.334 & 0.420 \\
\hline & $X$ & $X$ & & & 64.7 & 94.4 & 96.0 & 72.3 & 0.511 & 20 & 1 & 4.392 & 0.227 \\
\hline & & & $X$ & & 45.7 & 100.0 & $* 100.0$ & 36.0 & 0.766 & 20 & 1 & 4.334 & 0.420 \\
\hline & & & & $x$ & 82.8 & 11.8 & 67.5 & 98.7 & 0.050 & 20 & 1 & 0.260 & 0.478 \\
\hline & & & $x$ & $X$ & 73.4 & 77.7 & 87.6 & 84.9 & 0.370 & 20 & 1 & 2.579 & 0.199 \\
\hline & $X$ & $x$ & $x$ & $X$ & 68.1 & 90.2 & 93.6 & 77.2 & 0.464 & 20 & 1 & 3.696 & 0.205 \\
\hline & \multirow{2}{*}{\multicolumn{4}{|c|}{ Minimal $D_{N}$}} & 71.5 & 83.3 & 90.1 & 82.1 & 0.408 & 20 & 1 & 2.987 & 0.194 \\
\hline \multirow[t]{8}{*}{ IL2 } & & & & & 95.9 & 13.7 & 68.2 & 99.7 & 0.050 & 20 & 1 & 0.225 & 0.460 \\
\hline & & $X$ & & & 68.5 & * 100.0 & 100.0 & 75.2 & 0.511 & 20 & 1 & 12.959 & 0.200 \\
\hline & $X$ & $x$ & & & 85.5 & 95.5 & 97.4 & 91.3 & 0.391 & 20 & 1 & 4.858 & 0.088 \\
\hline & & & $X$ & & 68.5 & 100.0 & $* 100.0$ & 75.2 & 0.511 & 20 & 1 & 12.959 & 0.200 \\
\hline & & & & $x$ & 95.9 & 13.7 & 68.2 & 99.7 & 0.050 & 20 & 1 & 0.230 & 0.460 \\
\hline & & & $x$ & $X$ & 87.4 & 93.3 & 96.2 & 92.7 & 0.374 & 20 & 1 & 4.114 & 0.082 \\
\hline & $X$ & $X$ & $x$ & $X$ & 86.2 & 94.8 & 97.0 & 91.9 & 0.385 & 20 & 1 & 4.560 & 0.085 \\
\hline & \multicolumn{4}{|c|}{ Minimal $D_{N}$} & 88.0 & 92.3 & 95.7 & 93.2 & 0.367 & 20 & 1 & 3.865 & 0.082 \\
\hline
\end{tabular}

* Consideration of minimal area required to achieve complete (greater than $99.99 \%$ ) recovery of $\mathrm{CO}_{2}$.

When only one optimization objective was considered, the individual distance of that objective was minimized, whereas when the simultaneous optimization of more than one objective was taken into account, the target was the minimization of the sum of the individual distances to each specific objective. Finally, the results were compared to the situation where the objective was the minimization of the normalized distance for all of the objectives.

As expected, the consideration of just a single objective resulted in extreme values of the stage cut. On the one hand, the maximization of the $\mathrm{CO}_{2}$ purity (or the $\mathrm{CH}_{4}$ recovery) matched with the selection of the lowest cut stage value ( 0.05 was imposed as a restriction 
of the system). On the other hand, the maximal allowed value of the cut stage (0.95) was required to achieve the maximal $\mathrm{CH}_{4}$ purity (or the $\mathrm{CO}_{2}$ recovery). As the cut stage and corresponding membrane area increased, so did the $\mathrm{CH}_{4}$ purity as a consequence of the preferential permeation of $\mathrm{CO}_{2}$. Nevertheless, this reduced $\mathrm{CO}_{2}$ partial pressure promoted $\mathrm{CH}_{4}$ permeation through the membrane and decreased $\mathrm{CH}_{4}$ recovery [9]. In the case of the PDMS membrane, the design of a module with a 0.95 stage cut resulted in a $\mathrm{CH}_{4}$ purity of $99.2 \%$ and $99.8 \%$ for vacuum and pressurized conditions, respectively, with a $\mathrm{CO}_{2}$ recovery equal to $99.9 \%$ in both cases. The other two membranes, PDMSt and IL2, were able to able to attain a total $\mathrm{CO}_{2}$ recovery and pure $\mathrm{CH}_{4}$ (higher than $99.99 \%$ ) for stage cut values below the imposed upper limit in both vacuum and pressurized conditions: from 0.551 in the case of IL2 in pressurized conditions to 0.829 for PDMSt under vacuum conditions.

When multiobjective optimization was taken into account, the system required compromised optimal conditions that counterbalanced the different targets. Nevertheless, in the case of the PDMS membrane, extreme cut stage values were still an optimal solution under specific circumstances. For instance, the simultaneous optimization of $\mathrm{CH}_{4}$ purity and recovery was obtained when the stage cut value was equal to 0.05 (lowest allowed limit) for both vacuum and pressurized conditions. However, the optimization of $\mathrm{CO}_{2}$ purity and recovery required a reduction in the stage cut from its maximal allowed limit to 0.846 and 0.796 for vacuum and pressurized conditions, respectively. In all cases, for all membranes, the stage cut value to optimize $\mathrm{CO}_{2}$ purity and recovery was higher than the one resulting from the optimization of $\mathrm{CH}_{4}$ purity and recovery, although these values were close when the IL2 was employed under pressurized conditions. For this membrane, whereas the value of the stage cut of 0.391 optimized $\mathrm{CO}_{2}$ purity and recovery, the optimization of $\mathrm{CH}_{4}$ purity and recovery occurred for a stage cut value equal to 0.374 . Within this interval, the optimal value that minimized the sum of the individual distances of the four objectives simultaneously was found: a cut stage value equal to 0.385 allowed for the achievement of recovery percentages above $90 \%$ for both gases, with purity values equal to $86.2 \%$ and $97.0 \%$ for $\mathrm{CO}_{2}$ and $\mathrm{CH}_{4}$, respectively. The recovery and purity values attained with the PDMS and PDMSt membranes were lower than those of the IL2 membrane, which clearly demonstrated its higher potentiality.

The analysis of the values of the normalized distance of all of the solutions compiled in Tables 3 and 4 revealed some interesting facts. Firstly, the consideration of just an individual objective resulted in very extreme values, which were able to optimize the objective selected, but at the expense of the other objectives. These objectives that were not taken into account were maintained very far away from their targets, and the corresponding $D_{N}$ value was high. Moreover, the consideration of the conditions to minimize the sum of the individual distances did not match with the optimal conditions to attain the minimal $D_{N}$ value. In all cases, the optimal stage cut values for the minimal distance were lower than the values obtained to minimize the sum of the individual distances. Under these circumstances, the four recovery and purity values were more counterbalanced, avoiding the presence of a lower single value that can result in a distance penalty. In fact, the consideration of the four objectives simultaneously without the "distance-to-target" approach resulted in $D_{N}$ values higher than the case that considered only two objectives. For instance, the IL2 membrane showed lower $D_{N}$ values for the optimization of $\mathrm{CH}_{4}$ recovery and purity $(0.149$ and 0.082 for vacuum and pressurized conditions, respectively) than for the optimization of the four objectives ( 0.153 and 0.085 for vacuum and pressurized conditions, respectively). This fact confirmed the importance of the selection of a very effective tool to define the optimal conditions in multiobjective scenarios.

The pressure restrictions and feed composition had a great influence on the optimal conditions of the membrane modules. When the system operated under vacuum conditions, extensive membrane areas were required. Besides, since an adequate separation performance required a sufficient high pressure ratio (the ratio between feed and permeate pressures), severe vacuum conditions became necessary [45]. The influence of the maximal pressure value allowed in the feed side of the module on the optimal stage cut, recovery and 
purity values, as well as the resulting membrane areas, is shown in Figure 7. Once again, since the higher the upper limit for pressure, the higher the recovery and purity values, the value of $D_{N}$ decreased continuously as the maximal allowed pressure was increased (from 0.147 to 0.082 for 5 and $20 \mathrm{~atm}$, respectively). Only small variations in the optimal stage cut values appeared, ranging from 0.367 to 0.380 for 20 and $5 \mathrm{~atm}$, respectively. However, the most relevant issue was the membrane area required under optimal conditions. In addition to reduced recovery and purity percentages, the operation under lower pressure conditions implied the requirement of a huge membrane area. The required area increased from $3.9 \mathrm{~m}^{2}$ for $20 \mathrm{~atm}$ to $31.4 \mathrm{~m}^{2}$ in the case of $5 \mathrm{~atm}$. This great difference pointed to the selection of the highest possible pressure in the feed side of the membrane module in order to minimize the amount of membrane required to carry out the separation, which, in addition, resulted in the highest performance in terms of recovery and purity.

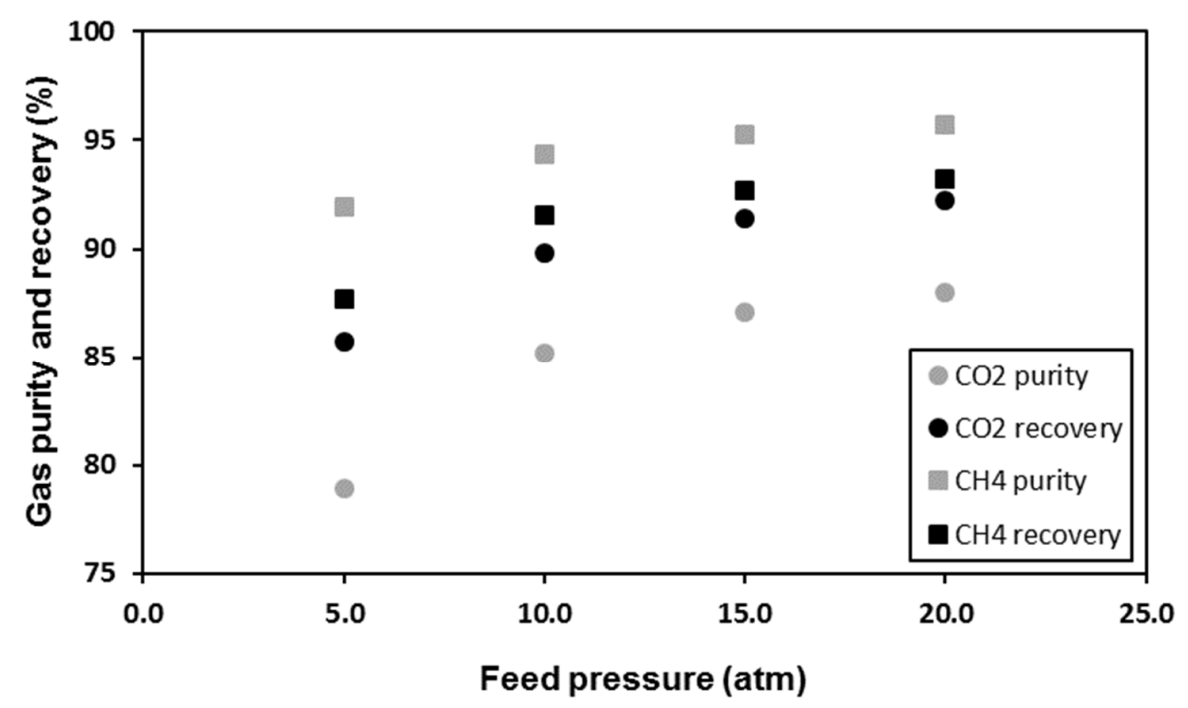

(a)

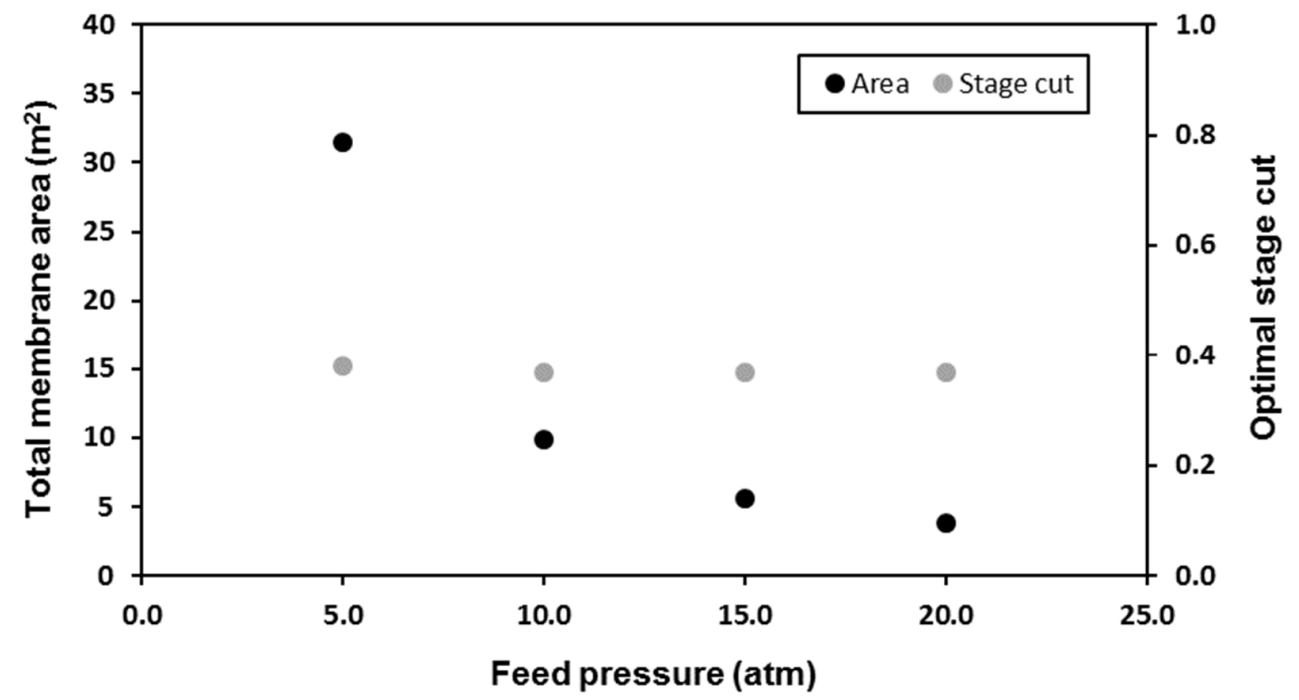

(b)

Figure 7. Influence of the maximal pressure value allowed in the feed side of the module on the optimal (a) recovery and purity and (b) stage cut and membrane area for the IL 2 membrane.

Another important factor that must be taken into consideration for the multiobjective optimization of the membrane modules is the feed composition. The influence of the feed 
composition on the optimal stage cut, recovery and purity values, as well as the resulting membrane areas, is shown in Figure 8. In this case, the multiobjective optimization revealed a different trend when compared to the case of the sensitivity analysis under the constant stage cut previously presented. Although the contradictory effects of the increased $\mathrm{CO}_{2}$ molar fraction in the feed composition were maintained, the process performance parameters affected were different. While both purities maintained the previously identified trend $\left(\mathrm{CO}_{2}\right.$ purity increased and $\mathrm{CH}_{4}$ decreased), the recovery values changed their tendencies. On the one hand, higher $\mathrm{CO}_{2}$ feed fractions involved an increased $\mathrm{CO}_{2}$ recovery, mainly as a consequence of increased values for the corresponding optimal stage cuts (from 0.244 with 0.20 feed fraction to 0.808 with 0.80 feed fraction). On the other hand, $\mathrm{CH}_{4}$ recovery followed the opposite trend, and lower values were obtained for high $\mathrm{CO}_{2}$ feed fractions (which is also a direct result of increased stage cuts, which implied a higher permeation of $\mathrm{CH}_{4}$ through the membrane).

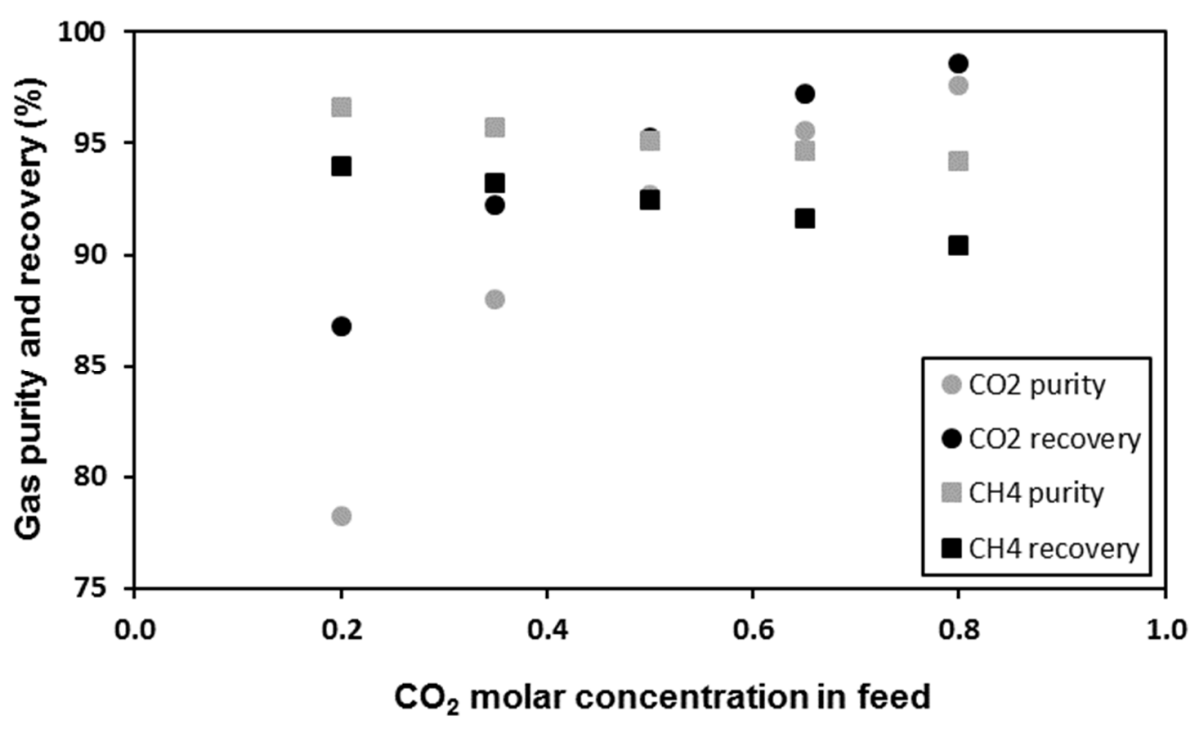

(a)

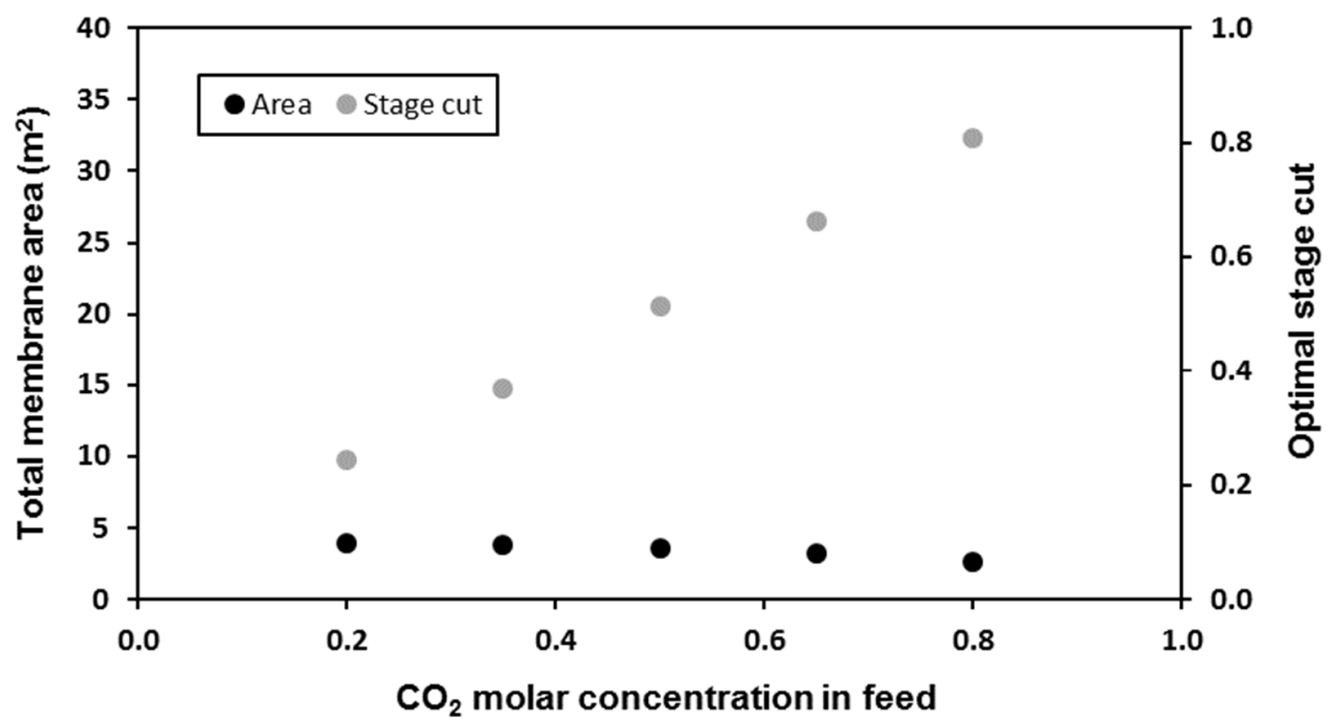

(b)

Figure 8. Influence of the feed $\mathrm{CO}_{2}$ molar fraction on the optimal (a) recovery and purity and (b) stage cut and membrane area for the IL2 membrane. 
As a result of the different evolutions followed by the purities and recoveries, the identification of the optimal feed composition for the IL2 membrane is not obvious (the optimal $D_{N}$ values for $0.20,0.35,0.50,0.65$ and $0.80 \mathrm{CO}_{2}$ feed fractions were $0.132,0.082$, $0.063,0.056$ and 0.058 , respectively). Therefore, the search for the optimal feed composition was carried out, and the result was a composition with a $0.69 \mathrm{CO}_{2}$ molar fraction. The resulting optimal $\mathrm{CO}_{2}$ feed fraction was far away from the typical biogas characteristics, with a $\mathrm{CO}_{2}$ content below $0.40[46,47]$, so the application of the IL2 membrane to other applications, such as the oil enhanced recovery, where feed streams with a $\mathrm{CO}_{2}$ fraction of around 0.75 are common [48], can also be suggested.

Another relevant aspect that must be highlighted is the evolution of the required membrane area. Although there was a continuous increasing of the optimal stage cut value, the membrane area followed a slight reduction: $4.0 \mathrm{~m}^{2}$ was required for a feed composition with $0.20 \mathrm{CO}_{2}$, whereas only $2.6 \mathrm{~m}^{2}$ was required when the module was fed with $0.80 \mathrm{CO}_{2}$. This fact can be explained by the enhanced permeation of $\mathrm{CO}_{2}$ when the $\mathrm{CO}_{2}$-rich stream was fed, which allowed for a higher partial pressure gradient of $\mathrm{CO}_{2}$ between both sides of the membranes.

Lastly, a comparison of the performance of the main membranes selected in this study to that of other $\mathrm{CO}_{2} / \mathrm{CH}_{4}$ mentioned by other researchers in some recent publications was carried out [49-51]. These referenced membranes were a generic polymeric blend membrane, an asymmetric polysulfone membrane and a polysulfone coated with a PDMS membrane, respectively. The results are compiled in Table 5 and clearly demonstrate the competitiveness of the IL2 when compared to other available membranes, since it showed the best technical performance in terms of the distance to the target. The comparison also revealed that, although the treatment of the virgin PDMS membrane was effective in significantly improving its performance, the resulting PDMSt was not yet able to surpass the performance of the other referenced membranes. Nevertheless, in all cases, the values of the purities obtained were not enough to fulfill the requirements imposed on $\mathrm{CO}_{2}$ and $\mathrm{CH}_{4}$ streams in order to be directly valorized, taking into account that purity values above $90 \%$ and $98 \%$ may be required for $\mathrm{CO}_{2}$ and $\mathrm{CH}_{4}$, respectively [52,53]. Therefore, the design of more advanced separation processes based on multiple stages of membranes modules would also be proposed [54], so further work to consider the design of this type of layouts with the most promising membrane modules will be performed.

Table 5. Comparison of the optimal process performance parameters of the PDMS, PDMSt and IL2 membranes to other innovative membranes from referenced studies.

\begin{tabular}{|c|c|c|c|c|c|c|c|c|c|c|c|}
\hline Membrane & $\begin{array}{l}\text { Permeability } \\
\text { (GPU) }\end{array}$ & $\begin{array}{l}\text { Selectivity } \\
\mathrm{CO}_{2} / \mathrm{CH}_{4}\end{array}$ & $\begin{array}{c}\mathrm{CO}_{2} \\
\text { Purity }\end{array}$ & $\begin{array}{c}\mathrm{CO}_{2} \\
\text { Recovery }\end{array}$ & $\begin{array}{c}\mathrm{CH}_{4} \\
\text { Purity }\end{array}$ & $\begin{array}{c}\mathrm{CH}_{4} \\
\text { Recovery }\end{array}$ & Stage Cut & $\underset{(\mathrm{atm})}{\mathbf{P}_{\mathrm{F}}}$ & $\underset{(\mathrm{atm})}{\mathrm{P}_{\mathrm{Q}}}$ & $\begin{array}{l}\text { Area } \\
\left(\mathrm{m}^{2}\right)\end{array}$ & $D_{N}$ \\
\hline PDMS & 266 & 3.1 & 49.1 & 84.8 & 86.6 & 52.7 & 0.604 & 20 & 1 & 0.681 & 0.362 \\
\hline PDMSt & 73.7 & 10.7 & 68.1 & 90.2 & 93.6 & 77.2 & 0.464 & 20 & 1 & 3.696 & 0.205 \\
\hline IL2 & 102 & 54.8 & 86.2 & 94.8 & 97.0 & 91.9 & 0.385 & 20 & 1 & 4.560 & 0.085 \\
\hline $\operatorname{Ref}[49]$ & 37 & 24.8 & 78.9 & 93.0 & 95.8 & 86.6 & 0.412 & 20 & 1 & 9.654 & 0.131 \\
\hline $\operatorname{Ref}[50]$ & 103 & 39 & 83.4 & 94.1 & 96.6 & 89.9 & 0.395 & 20 & 1 & 4.023 & 0.103 \\
\hline $\operatorname{Ref}[51]$ & 158 & 27 & 79.8 & 93.2 & 96.0 & 87.3 & 0.409 & 20 & 1 & 2.324 & 0.125 \\
\hline
\end{tabular}

\section{Conclusions}

The mathematical model developed in this work has been successfully applied to represent the performance of membrane separation units with two types of innovative membranes for $\mathrm{CO}_{2} / \mathrm{CH}_{4}$ separation. After the validation of the model with experimental data, it was used to simulate the performance of the separation process by modified commercial PDMS and non-commercial IL-chitosan composite membranes under different design and operation conditions, paying attention to the effects due to different pressures, stage cuts and feed compositions.

The optimization of the separation process, considering both gases in the feed mixture as targets, resulted in the definition of different multiobjective scenarios. A "distance-totarget" approach was selected for the simultaneous consideration of all of the objectives, and the results demonstrated that the maximal allowed feed pressure must be selected for 
the optimization of the separation, while the optimal stage cut was dependent on each specific membrane.

The obtained results allowed us to conclude that the ionic liquid-chitosan composite membranes (IL-CS/PES) improved the performance of other innovative membranes, with purity and recovery percentage values of $86 \%$ and $95 \%$, respectively, for $\mathrm{CO}_{2}$ in the permeate stream, and $97 \%$ and $92 \%$ for $\mathrm{CH}_{4}$ in the retentate stream. The multiobjective optimization calculations allowed us to determine the process design and performance parameters, such as the membrane area, pressure ratio and stage cut required to achieve maximum values for components separation, in terms of purity and recovery for both components.

In addition, each membrane presented an optimal feed composition, which should be taken into account to select the most adequate membrane for a determined application. The modification of the PDMS membrane by treatment with $\mathrm{NaOH}$ represented an effective way to improve the separation performance, and the improved IL-chitosan membrane appeared more competitive than other innovative membranes presented in referenced previous studies. If the separation process performance in terms of purity and recovery would not be enough to obtain streams that fulfill the requirements imposed on $\mathrm{CO}_{2}$ and $\mathrm{CH}_{4}$ direct valorization, further efforts would also be considered toward the design of more complex multi-stage separation processes. The applied optimization methodology was proposed as a useful tool to advance the implementation of the membrane separation systems, in conjunction with the development and innovation efforts of membrane materials.

Author Contributions: Conceptualization, R.A. and A.G.; methodology, R.A., C.C.-C. and A.G.; software, R.A.; validation, R.A., C.C.-C. and A.G.; formal analysis, R.A., C.C.-C. and A.G.; investigation, R.A., C.C.-C. and A.G.; data curation, C.C.-C. and A.G.; writing-original draft preparation, R.A.; writing-review and editing, R.A., C.C.-C. and A.G.; supervision, C.C.-C. and A.G.; project administration, A.G.; funding acquisition, A.G. All authors have read and agreed to the published version of the manuscript.

Funding: This work was funded by the Spanish Ministry of Science and Innovation Project PID2019108136RB-C31/AEI/10.13039/501100011033. MCIN/AEI/10.13039/501100011033 and the "European Union NextGeneration EU/PRTR" are also thanked for the Grant EIN2020-112319/AEI/ $10.13039 / 501100011033$.

Institutional Review Board Statement: Not applicable.

Informed Consent Statement: Not applicable.

Conflicts of Interest: The authors declare no conflict of interest.

\section{Nomenclature}

$C_{i} \quad$ Components of the vector to be optimized

$D \quad$ Euclidean distance

$D_{N} \quad$ Normalized distance to target (-)

$F_{\text {in }} \quad$ Total feed flowrate to the module $\left(\mathrm{m}^{3}{ }_{(\mathrm{STP})} / \mathrm{h}\right)$

$F_{\text {Ain }} \quad$ Flow of the most permeable compound A in the feed $\left(\mathrm{m}^{3}(\mathrm{STP}) / \mathrm{h}\right)$

$F_{\text {Bin }} \quad$ Flow of the least permeable compound B in the feed $\left(\mathrm{m}^{3}(\mathrm{STP}) / \mathrm{h}\right)$

$F_{\text {in(i) }} \quad$ Total feed flowrate to the cell i $\left(\mathrm{m}^{3}{ }_{(\mathrm{STP})} / \mathrm{h}\right)$

$F_{\text {out }} \quad$ Total retentate flowrate leaving the module $\left(\mathrm{m}^{3}{ }_{(\mathrm{STP})} / \mathrm{h}\right)$

$F_{\text {Aout }} \quad$ Flow of the most permeable compound A in the final retentate $\left(\mathrm{m}^{3}(\mathrm{STP}) / \mathrm{h}\right)$

$F_{\text {Bout }} \quad$ Flow of the least permeable compound B in the final retentate $\left(\mathrm{m}^{3}(\mathrm{STP}) / \mathrm{h}\right)$

$F_{\text {out }(i)}$ Total retentate flowrate leaving the cell $\mathrm{i}\left(\mathrm{m}^{3}(\mathrm{STP}) / \mathrm{h}\right)$

$G_{i} \quad$ Components of the target vector

$J_{(i)} \quad$ Total gas flowrate through the membrane in cell $\mathrm{i}\left(\mathrm{m}^{3}{ }_{(\mathrm{STP})} / \mathrm{h}\right)$

$J_{A(i)} \quad$ Flow of the most permeable compound A through the membrane in cell $\mathrm{i}\left(\mathrm{m}^{3}(\mathrm{STP}) / \mathrm{h}\right)$

$J_{B(i)} \quad$ Flow of the least permeable compound B through the membrane in cell $\mathrm{i}\left(\mathrm{m}^{3}(\mathrm{STP}) / \mathrm{h}\right)$

$n \quad$ Number of objectives to be optimized (-)

$\mathrm{P}_{\mathrm{F}} \quad$ Pressure in the retentate lumen side (atm) 


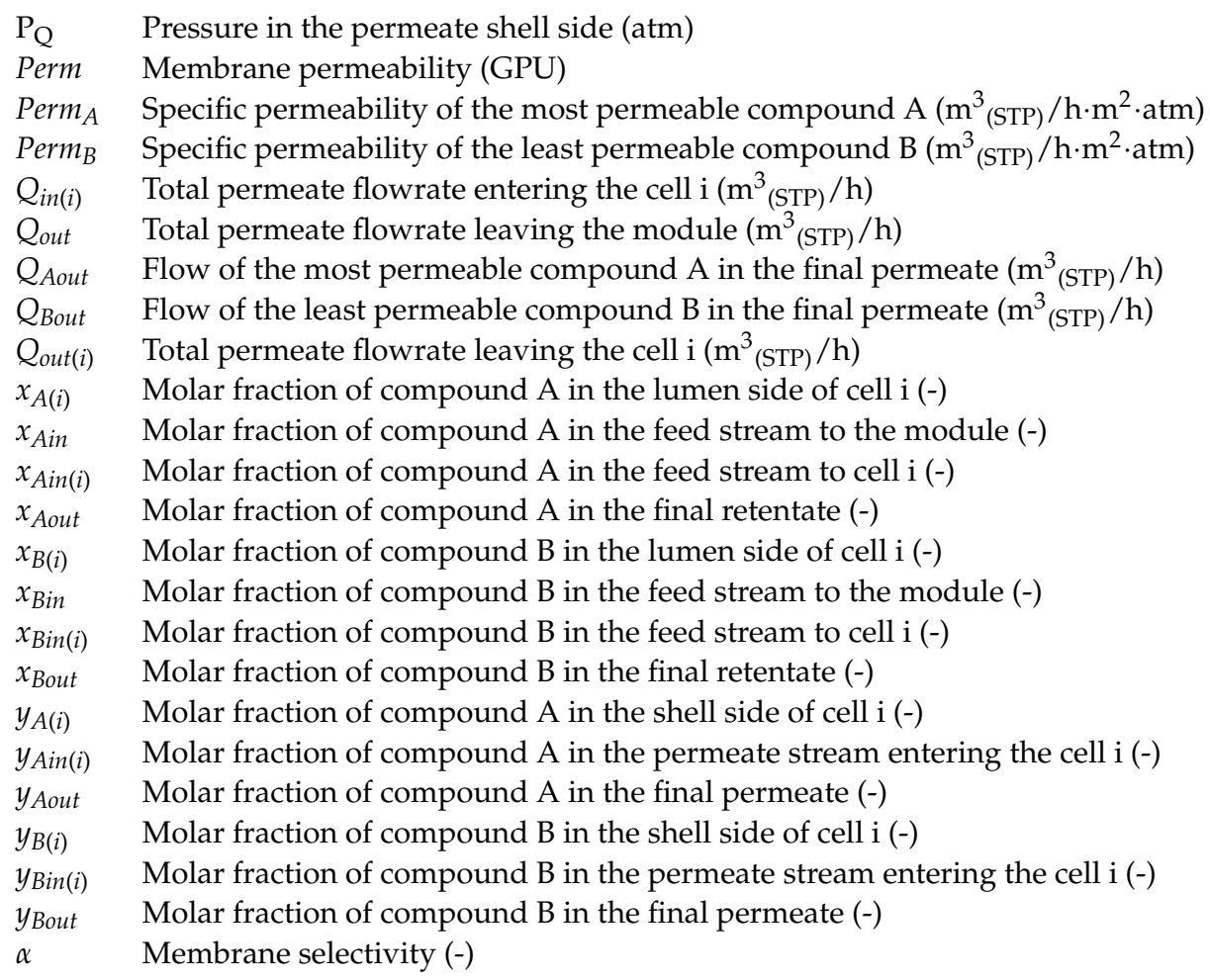

\section{References}

1. Salestan, S.K.; Pirzadeh, K.; Rahimpour, A.; Abedini, R. Poly (ether-block amide) thin-film membranes containing functionalized MIL-101 MOFs for efficient separation of $\mathrm{CO}_{2} / \mathrm{CH}_{4}$. J. Environ. Chem. Eng. 2021, 9, 105820. [CrossRef]

2. Liao, Z.; Hu, Y.; Wang, J.; Yang, Y.; You, F. Systematic design and optimization of a membrane-cryogenic hybrid system for $\mathrm{CO}_{2}$ capture. ACS Sustain. Chem. Eng. 2019, 7, 17186-17197. [CrossRef]

3. Ullah Khan, I.; Hafiz Dzarfan Othman, M.; Hashim, H.; Matsuura, T.; Ismail, A.F.; Rezaei-DashtArzhandi, M.; Wan Azelee, I. Biogas as a renewable energy fuel-A review of biogas upgrading, utilisation and storage. Energy Convers. Manag. 2017, 150, 277-294. [CrossRef]

4. Sahota, S.; Shah, G.; Ghosh, P.; Kapoor, R.; Sengupta, S.; Singh, P.; Vijay, V.; Sahay, A.; Vijay, V.K.; Thakur, I.S. Review of trends in biogas upgradation technologies and future perspectives. Bioresour. Technol. Rep. 2018, 1, 79-88. [CrossRef]

5. Galizia, M.; Chi, W.S.; Smith, Z.P.; Merkel, T.C.; Baker, R.W.; Freeman, B.D. 50th Anniversary Perspective: Polymers and Mixed Matrix Membranes for Gas and Vapor Separation: A Review and Prospective Opportunities. Macromolecules 2017, 50, 7809-7843. [CrossRef]

6. Basu, S.; Khan, A.L.; Cano-Odena, A.; Liu, C.; Vankelecom, I.F.J. Membrane-based technologies for biogas separations. Chem. Soc. Rev. 2010, 39, 750-768. [CrossRef] [PubMed]

7. Ozturk, B.; Demirciyeva, F. Comparison of biogas upgrading performances of different mixed matrix membranes. Chem. Eng. J. 2013, 222, 209-217. [CrossRef]

8. Scholz, M.; Melin, T.; Wessling, M. Transforming biogas into biomethane using membrane technology. Renew. Sustain. Energy Rev. 2013, 17, 199-212. [CrossRef]

9. Cerveira, G.S.; Borges, C.P.; de Kronemberger, F.A. Gas permeation applied to biogas upgrading using cellulose acetate and polydimethylsiloxane membranes. J. Clean. Prod. 2018, 187, 830-838. [CrossRef]

10. Chen, X.Y.; Vinh-Thang, H.; Ramirez, A.A.; Rodrigue, D.; Kaliaguine, S. Membrane gas separation technologies for biogas upgrading. RSC Adv. 2015, 5, 24399-24448. [CrossRef]

11. Xiao, W.; Gao, P.; Dai, Y.; Ruan, X.; Jiang, X.; Wu, X.; Fang, Y.; He, G. Effciency separation process of $\mathrm{H}_{2} / \mathrm{CO}_{2} / \mathrm{CH}_{4}$ mixtures by a hollow fiber dual membrane separator. Processes 2020, 8, 560. [CrossRef]

12. Zhang, Y.; Sunarso, J.; Liu, S.; Wang, R. Current status and development of membranes for $\mathrm{CO}_{2} / \mathrm{CH}_{4}$ separation: A review. Int. J. Greenh. Gas Control 2013, 12, 84-107. [CrossRef]

13. Robeson, L.M. The upper bound revisited. J. Membr. Sci. 2008, 320, 390-400. [CrossRef]

14. Robeson, L.M.; Dose, M.E.; Freeman, B.D.; Paul, D.R. Analysis of the transport properties of thermally rearranged (TR) polymers and polymers of intrinsic microporosity (PIM) relative to upper bound performance. J. Membr. Sci. 2017, 525, 18-24. [CrossRef]

15. Comesaña-Gándara, B.; Chen, J.; Bezzu, C.G.; Carta, M.; Rose, I.; Ferrari, M.C.; Esposito, E.; Fuoco, A.; Jansen, J.C.; McKeown, N.B. Redefining the Robeson upper bounds for $\mathrm{CO}_{2} / \mathrm{CH}_{4}$ and $\mathrm{CO}_{2} / \mathrm{N}_{2}$ separations using a series of ultrapermeable benzotriptycenebased polymers of intrinsic microporosity. Energy Environ. Sci. 2019, 12, 2733-2740. [CrossRef] 
16. Park, H.B.; Kamcev, J.; Robeson, L.M.; Elimelech, M.; Freeman, B.D. Maximizing the right stuff: The trade-off between membrane permeability and selectivity. Science 2017, 356, 1138-1148. [CrossRef] [PubMed]

17. Friess, K.; Lanč, M.; Pilnáček, K.; Fíla, V.; Vopička, O.; Sedláková, Z.; Cowan, M.G.; McDanel, W.M.; Noble, R.D.; Gin, D.L.; et al. $\mathrm{CO}_{2} / \mathrm{CH}_{4}$ separation performance of ionic-liquid-based epoxy-amine ion gel membranes under mixed feed conditions relevant to biogas processing. J. Membr. Sci. 2017, 528, 64-71. [CrossRef]

18. Brunetti, A.; Cersosimo, M.; Kim, J.S.; Dong, G.; Fontananova, E.; Lee, Y.M.; Drioli, E.; Barbieri, G. Thermally rearranged mixed matrix membranes for $\mathrm{CO}_{2}$ separation: An aging study. Int. J. Greenh. Gas Control 2017, 61, 16-26. [CrossRef]

19. Qin, Y.; Xu, L.; Liu, L.; Deng, X.; Gao, Y.; Ding, Z. Ultrathin porous amine-based solid adsorbent incorporated zeolitic imidazolate framework-8 membrane for gas separation. RSC Adv. 2021, 11, 28863-28875. [CrossRef]

20. Thomas, A.; Ahamed, R.; Prakash, M. Selection of a suitable ZIF-8/ionic liquid (IL) based composite for selective $\mathrm{CO}_{2}$ capture: The role of anions at the interface. RSC Adv. 2020, 10, 39160-39170. [CrossRef]

21. Rezakazemi, M.; Heydari, I.; Zhang, Z. Hybrid systems: Combining membrane and absorption technologies leads to more efficient acid gases $\left(\mathrm{CO}_{2}\right.$ and $\left.\mathrm{H}_{2} \mathrm{~S}\right)$ removal from natural gas. J. $\mathrm{CO}_{2}$ Util. 2017, 18, 362-369. [CrossRef]

22. Sampaio, A.M.; Nabais, A.R.; Tomé, L.C.; Neves, L.A. Impact of MOF-5 on Pyrrolidinium-Based Poly(ionic liquid)/Ionic Liquid Membranes for Biogas Upgrading. Ind. Eng. Chem. Res. 2020, 59, 308-317. [CrossRef]

23. Ebadi Amooghin, A.; Mashhadikhan, S.; Sanaeepur, H.; Moghadassi, A.; Matsuura, T.; Ramakrishna, S. Substantial breakthroughs on function-led design of advanced materials used in mixed matrix membranes (MMMs): A new horizon for efficient $\mathrm{CO}_{2}$ separation. Prog. Mater. Sci. 2019, 102, 222-295. [CrossRef]

24. Casado-Coterillo, C.; Fernández-Barquín, A.; Irabien, A. Effect of humidity on $\mathrm{CO}_{2} / \mathrm{N}_{2}$ and $\mathrm{CO}_{2} / \mathrm{CH}_{4}$ separation using novel robust mixed matrix composite hollow fiber membranes: Experimental and model evaluation. Membranes 2020, 10, 6. [CrossRef]

25. Ameen, A.W.; Budd, P.M.; Gorgojo, P. Superglassy polymers to treat natural gas by hybrid membrane/amine processes: Can fillers help? Membranes 2020, 10, 413. [CrossRef] [PubMed]

26. Fernández-Barquín, A.; Rea, R.; Venturi, D.; Giacinti-Baschetti, M.; De Angelis, M.G.; Casado-Coterillo, C.; Irabien, Á. Effect of relative humidity on the gas transport properties of zeolite A/PTMSP mixed matrix membranes. RSC Adv. 2018, 8, 3536-3546. [CrossRef]

27. Casado-Coterillo, C. Mixed matrix membranes. Membranes 2019, 9, 149. [CrossRef] [PubMed]

28. Casado-Coterillo, C.; Garea, A.; Irabien, Á. Effect of water and organic pollutant in $\mathrm{CO}_{2} / \mathrm{CH}_{4}$ separation using hydrophilic and hydrophobic composite membranes. Membranes 2020, 10, 405. [CrossRef]

29. Dai, Z.; Ansaloni, L.; Deng, L. Recent advances in multi-layer composite polymeric membranes for $\mathrm{CO}_{2}$ separation: A review. Green Energy Environ. 2016, 1, 102-128. [CrossRef]

30. Ohs, B.; Lohaus, J.; Wessling, M. Optimization of membrane based nitrogen removal from natural gas. J. Membr. Sci. 2016, 498, 291-301. [CrossRef]

31. Nasir, R.; Ahmad, N.N.R.; Mukhtar, H.; Mohshim, D.F. Effect of ionic liquid inclusion and amino-functionalized SAPO-34 on the performance of mixed matrix membranes for $\mathrm{CO}_{2} / \mathrm{CH}_{4}$ separation. J. Environ. Chem. Eng. 2018, 6, 2363-2368. [CrossRef]

32. Kammakakam, I.; Bara, J.E.; Jackson, E.M.; Lertxundi, J.; Mecerreyes, D.; Tomé, L.C. Tailored $\mathrm{CO}_{2}$-Philic Anionic Poly(ionic liquid) Composite Membranes: Synthesis, Characterization, and Gas Transport Properties. ACS Sustain. Chem. Eng. 2020, 8 , 5954-5965. [CrossRef]

33. Turgut, O.; Murat, A.E. Generating pareto surface for multi objective integer programming problems with stochastic objective coefficients. Procedia Comput. Sci. 2011, 6, 46-51. [CrossRef]

34. Abejón, R.; Garea, A.; Irabien, A. Multiobjective optimization of membrane processes for chemicals ultrapurification. Comput. Aided Chem. Eng. 2012, 30, 542-546. [CrossRef]

35. Abejón, R.; Vázquez-Rowe, I.; Bala, A.; Fullana-i-Palmer, P.; MaríaMargallo; Aldaco, R. Application of the "Distance to Target" Approach to the Multiobjective Optimization of Nutritional and Economic Costs due to Food Loss and Waste. Comput. Aided Chem. Eng. 2020, 48, 1681-1686. [CrossRef]

36. Kundu, P.K.; Chakma, A.; Feng, X. Simulation of binary gas separation with asymmetric hollow fibre membranes and case studies of air separation. Can. J. Chem. Eng. 2011, 90, 1253-1268. [CrossRef]

37. Coker, D.T.; Freeman, B.D.; Fleming, G.K. Modeling multicomponent gas separation using hollow-fiber membrane contactors. AIChE J. 1998, 44, 1289-1302. [CrossRef]

38. Limleamthong, P.; Guillén-Gosálbez, G. Rigorous analysis of Pareto fronts in sustainability studies based on bilevel optimization: Application to the redesign of the UK electricity mix. J. Clean. Prod. 2017, 164, 1602-1613. [CrossRef]

39. Schädler, P.; Berdugo, J.D.; Hanne, T.; Dornberger, R. A Distance-Based Pareto Evolutionary Algorithm Based on SPEA for Combinatorial Problems. In Proceedings of the 4th International Symposium on Computational and Business Intelligence, Windisch, Switzerland, 5-7 September 2016; pp. 112-117.

40. Feng, X.; Ivory, J.; Rajan, V.S.V. Air separation by integrally asymmetric hollow-fiber membranes. AIChE J. 1999, 45, 2142-2152. [CrossRef]

41. Altintas, C.; Keskin, S. Molecular Simulations of MOF Membranes and Performance Predictions of MOF/Polymer Mixed Matrix Membranes for $\mathrm{CO}_{2} / \mathrm{CH}_{4}$ Separations. ACS Sustain. Chem. Eng. 2019, 7, 2739-2750. [CrossRef] 
42. Fernández-Barquín, A.; Casado-Coterillo, C.; Etxeberria-Benavides, M.; Zuñiga, J.; Irabien, A. Comparison of Flat and HollowFiber Mixed-Matrix Composite Membranes for $\mathrm{CO}_{2}$ Separation with Temperature. Chem. Eng. Technol. 2017, 40, 997-1007. [CrossRef]

43. Scholz, M.; Alders, M.; Lohaus, T.; Wessling, M. Structural optimization of membrane-based biogas upgrading processes. J. Membr. Sci. 2015, 474, 1-10. [CrossRef]

44. Harasimowicz, M.; Orluk, P.; Zakrzewska-Trznadel, G.; Chmielewski, A.G. Application of polyimide membranes for biogas purification and enrichment. J. Hazard. Mater. 2007, 144, 698-702. [CrossRef]

45. Molino, A.; Nanna, F.; Migliori, M.; Iovane, P.; Ding, Y.; Bikson, B. Experimental and simulation results for biomethane production using peek hollow fiber membrane. Fuel 2013, 112, 489-493. [CrossRef]

46. Melone, L.; Giorno, L.; Brunetti, A.; Barbieri, G. Analysis of membrane unit performance in presence of wet $\mathrm{CO}_{2}$-containing mixtures. Chem. Eng. Res. Des. 2020, 153, 721-727. [CrossRef]

47. Vilardi, G.; Bassano, C.; Deiana, P.; Verdone, N. Exergy and energy analysis of biogas upgrading by pressure swing adsorption: Dynamic analysis of the process. Energy Convers. Manag. 2020, 226, 113482. [CrossRef]

48. Zhang, C.; Sheng, M.; Hu, Y.; Yuan, Y.; Kang, Y.; Sun, X.; Wang, T.; Li, Q.; Zhao, X.; Wang, Z. Efficient facilitated transport polymer membrane for $\mathrm{CO}_{2} / \mathrm{CH}_{4}$ separation from oilfield associated gas. Membranes 2021, 11, 118. [CrossRef] [PubMed]

49. Aliaga-Vicente, A.; Caballero, J.A.; Fernández-Torres, J. Synthesis and Optimization of Membrane Cascade for Gas Separation via Mixed-Integer Nonlinear Programming. AIChE J. 2017, 63, 1989-2006. [CrossRef]

50. Seong, M.S.; Kong, C.I.; Park, B.R.; Lee, Y.; Na, B.K.; Kim, J.H. Optimization of pilot-scale 3-stage membrane process using asymmetric polysulfone hollow fiber membranes for production of high-purity $\mathrm{CH}_{4}$ and $\mathrm{CO}_{2}$ from crude biogas. Chem. Eng. J. 2020, 384, 123342. [CrossRef]

51. Shin, M.S.; Jung, K.H.; Kwag, J.H.; Jeon, Y.W. Biogas separation using a membrane gas separator: Focus on $\mathrm{CO}_{2}$ upgrading without $\mathrm{CH}_{4}$ loss. Process Saf. Environ. Prot. 2019, 129, 348-358. [CrossRef]

52. Favre, E.; Bounaceur, R.; Roizard, D. Biogas, membranes and carbon dioxide capture. J. Membr. Sci. 2009, 328, 11-14. [CrossRef]

53. Singhal, S.; Agarwal, S.; Arora, S.; Sharma, P.; Singhal, N. Upgrading techniques for transformation of biogas to bio-CNG: A review. Int. J. Energy Res. 2017, 41, 1657-1669. [CrossRef]

54. Han, Y.; Yang, Y.; Winston Ho, W.S. Recent progress in the engineering of polymeric membranes for $\mathrm{CO}_{2}$ capture from flue gas. Membranes 2020, 10, 365. [CrossRef] [PubMed] 